\title{
Article \\ Chemical and Microstructural Properties of Designed Cohesive M-S-H Pastes
}

\author{
Charlotte Dewitte ${ }^{1,2}$, Alexandra Bertron ${ }^{2, *} \mathbb{D}$, Mejdi Neji $^{1}$, Laurie Lacarrière ${ }^{2}$ and Alexandre Dauzères ${ }^{1}$ \\ 1 Institut de Radioprotection et de Sûreté Nucléaire (IRSN), PSE-ENV/SEDRE/LETIS, \\ 92260 Fontenay-aux-Roses, France; charlotte.dewitte@irsn.fr (C.D.); mejdi.neji@irsn.fr (M.N.); \\ alexandre.dauzeres@irsn.fr (A.D.) \\ 2 LMDC (Laboratoire Matériaux et Durabilité des Constructions), Université de Toulouse, UPS, INSA, \\ 135 Avenue de Rangueil, CEDEX 04, 31077 Toulouse, France; laurie.lacarriere@insa-toulouse.fr \\ * Correspondence: bertron@insa-toulouse.fr
}

check for updates

Citation: Dewitte, C.; Bertron, A.; Neji, M.; Lacarrière, L.; Dauzères, A. Chemical and Microstructural Properties of Designed Cohesive M-S-H Pastes. Materials 2022, 15, 547. https://doi.org/10.3390/ ma15020547

Academic Editor: Eddie Koenders

Received: 21 November 2021

Accepted: 24 December 2021

Published: 12 January 2022

Publisher's Note: MDPI stays neutral with regard to jurisdictional claims in published maps and institutional affiliations.

Copyright: (c) 2022 by the authors. Licensee MDPI, Basel, Switzerland. This article is an open access article distributed under the terms and conditions of the Creative Commons Attribution (CC BY) license (https:// creativecommons.org/licenses/by/ $4.0 /)$.

\begin{abstract}
Concretes can be exposed to a magnesium attack in several environments leading to the formation of magnesium silicate hydrates (M-S-H) and brucite (MH). The formation of M-S-H is likely to alter the properties of the cement matrix because it is linked to the decalcification of C-S-H. However, relatively few data on M-S-H exist in the literature. In order to characterize, physically and mechanically, the M-S-H phase, pure M-S-H cohesive pastes are needed. This work studies the formation of cohesive M-S-H pastes made with $\mathrm{MgO}$-to- $\mathrm{SiO}_{2}$ atomic ratios of $0.78,1$ and 1.3, from two types of silica (silica fume or colloidal silica) and under $20{ }^{\circ} \mathrm{C}$ and $50{ }^{\circ} \mathrm{C}$ thermal curing. $\mathrm{X}$-ray diffraction and thermogravimetric analyses confirmed that the consumption of brucite and the formation of M-S-H were quicker with a $50{ }^{\circ} \mathrm{C}$ curing. Energy-dispersive X-ray spectroscopy and microtomography showed that colloidal silica enabled a better distribution of the particles than silica fume. Microstructural characterizations were conducted under the protocol with colloidal silica and $50{ }^{\circ} \mathrm{C}$ thermal curing. Porosity investigations allowed to describe the M-S-H pastes as highly porous materials with a low content of micropores in comparison with mesopores. The type of mixing influenced the mesopore size distribution.
\end{abstract}

Keywords: magnesium silicate hydrates (M-S-H); X-ray diffraction; thermogravimetric analysis; autoradiography; physisorption; mercury porosity

\section{Introduction}

Magnesium (Mg) enrichment of cementitious materials has been observed in civil engineering construction exposed to three types of aqueous environments: seawater, soft water (in contact with marine construction and dams [1-5]), and pore water of clayey rock (in contact with concrete intended for disposal galleries or bentonite plug support blocks in deep radioactive waste repositories [6-12]). Real-life aqueous environments are often multi-component, generating a combination of chemical attacks on concrete. In seawater, $\mathrm{Mg}$ attacks act in conjunction with carbonate, chloride and sulphate ions $[2,4,13,14]$. In groundwater environments and / or geological environments intended for radioactive waste repository, Mg enrichment-associated with decalcification, carbonation and sulphate attack - has been reported at the interface between cement-based materials and clayey rock [6-12]. The same perturbation has been observed during contact between soft water and dams [5]. The degradation can be divided into several physical zones where the action of sulphates, decalcification and carbonation combine with $\mathrm{Mg}$ enrichment.

During $\mathrm{Mg}$ attacks, magnesium reacts mainly with the calcium phases of the cement matrix - portlandite $\left(\mathrm{Ca}(\mathrm{OH})_{2}\right.$ or $\mathrm{CH}$ in cement notation) and calcium silicate hydrates (C-S-H) in particular-to form brucite and magnesium silicate hydrates (M-S-H). For ordinary binders with a high calcium-to-silicon ratio ( $\mathrm{Ca} / \mathrm{Si})$, i.e., Portland cements, $\mathrm{Mg}$ attacks have been evidenced by the formation of brucite from the dissolution of portlandite. 
Brucite precipitates first at the surface of concrete specimens, reducing the kinetics of further species diffusion. In the long term, a slow decalcification of C-S-H leads to the formation of M-S-H $[2,6,9,15]$.

For binders with a low $\mathrm{Ca} / \mathrm{Si}$ ratio, the $\mathrm{Mg}$ attack mechanisms are different. These binders have been developed for the following purposes: (i) to reduce heat release leading to early-age cracking risks for massive structures [16]; (ii) to improve the long-term mechanical performance, durability and sustainability of concrete (to resist penetration of chloride ions, for example) [17,18]; and (iii) to reduce environmental impact [19]. Part of the clinker is substituted by several materials such as fly ash, silica fume or slag. The consequences of these substitutions are multiple: improvement of the granular skeleton; reduction of heat release by hydration reactions; reduction of $\mathrm{pH}$ of the interstitial solution [20]; reduction of the $\mathrm{Ca} / \mathrm{Si}$ ratio of hydrated products [21], etc. These low-heat or low-pH binders are taken into account for the construction of dams [22,23] or the construction of a deep disposal for radioactive waste $[7,24]$, seeking to preserve the clayey rock from the alkaline plume and/or to decrease the thermal effect during concrete hardening. The $\mathrm{pH}$ of the matrices obtained by hydration of these binders is low $(11<\mathrm{pH}<12.5)[25]$ and the pastes obtained do not contain much-or any-portlandite. Mg attacks on such materials are characterized by a fast decalcification of C-S-H and the formation of M-S-H [6].

When hydrated cement pastes (containing portlandite, aluminates and C-S-H) are subjected to pure water, decalcification has deleterious effects on the physical and mechanical properties of concrete, mainly by increasing porosity and decreasing mechanical performance [26-31]. In the case of magnesium-rich water, the positive or negative effect of $\mathrm{M}-\mathrm{S}-\mathrm{H}$ formation on the mechanical and physical properties degraded by decalcification is not known.

In degraded cement pastes or concrete, M-S-H were found to be intermixed with other phases, thus complicating the identification of their intrinsic properties $[5,11,12,24]$. Synthetic M-S-H powders (produced from $\mathrm{MgO}, \mathrm{SiO}_{2}$ and water) have already been developed to analyze the formation of the phase (in terms of formation kinetics and equilibrium constants), its chemical and mineralogical characteristics, and the structure of the M-S-H gel [32-43]. When water, $\mathrm{MgO}$ and $\mathrm{SiO}_{2}$ react, the $\mathrm{M}-\mathrm{S}-\mathrm{H}$ are not the phase preferably formed at an early stage. The main precipitated phase is brucite $\left(\mathrm{Mg}(\mathrm{OH})_{2}\right)$ due to the slower dissolution of silica compared to magnesium [37,44]. For reactive transport modeling (Hytec, for instance), it is necessary to know the physical properties of M-S-H to understand how the porosity evolves in decalcified materials when M-S-H precipitate. In order to characterize the microstructure of M-S-H gels, cohesive M-S-H pastes are needed.

The preparation of pure cohesive M-S-H pastes faces two main obstacles: (i) the difficulty to obtain cohesive pastes with representative porosity and microstructure that allow the physical and mechanical characterization of in situ, experimentally observed M-S-H; and (ii) the difficulty to obtain materials containing only M-S-H phases within a reasonable time (a few months).

Concerning the first aspect, two protocols for manufacturing M-S-H pastes have been developed in the literature to meet the high need of water of $\mathrm{MgO}$ powder [45], either using a high water/binder ratio $(\mathrm{w} / \mathrm{b}=2)[44,46]$ or sodium hexametaphosphate (NaHMP), a superplasticizer $(0.025-0.3 \mathrm{~g}$ in $10 \mathrm{~g}$ of water, with $0.4<\mathrm{w} / \mathrm{b}<0.8)[45,47]$. The influence of NaHMP on the structure of M-S-H and other hydrated phases has been studied by several authors [48-50]. Although it led to a better rheological behavior and the formation of M-S-H over brucite (due to the adsorption of phosphate species on $\mathrm{MgO}$, which inhibits the nucleation of the $\mathrm{Mg}(\mathrm{OH})_{2}$ ), the formation of secondary phases (such as $\left.\left[6 \mathrm{MgOH}^{+} \cdot\left(\mathrm{PO}_{3}\right)_{6}^{6-}\right]\right)[49,50]$ and minor changes in the structure of M-S-H gels have been observed $[48,50]$. NaHMP could thus cause chemical and mineralogical differences between in situ precipitated M-S-H and synthetized M-S-H. At high w/b ratios, the structure could be modified. Excess of water results in the modification of the porous network through the creation of pores, air voids, etc., which alters species diffusion. Moreover, high porosity weakens the material and complicates mechanical characterization. 
Concerning the second aspect, literature on M-S-H powder synthesis has shown that the mechanism of M-S-H formation from the reaction between silica fume and $\mathrm{MgO}$ is a slow process that lasts at least $2-3$ years at $20^{\circ} \mathrm{C}[34,43]$. Several researchers $[36,39,45,46]$ have reported that M-S-H are not the only phase formed during the initial contact between $\mathrm{MgO}$, silica fume and water at $20^{\circ} \mathrm{C}$. Silica fume dissolves more slowly than $\mathrm{MgO}$ reacts, leading to thermodynamic conditions favorable to brucite formation (low silicon concentration in the solution). Brucite is subsequently consumed, reacting with the amorphous silica to form M-S-H. This process leads to a very long synthesis. This problem can be circumvented by increasing the curing temperature as shown by Bernard [36], who obtained M-S-H powders cured at $50{ }^{\circ} \mathrm{C}$ or $70^{\circ} \mathrm{C}$ comparable to those cured at $20^{\circ} \mathrm{C}$ but with a shorter hydration time. Bernard showed that a cure at $50^{\circ} \mathrm{C}$ or $70{ }^{\circ} \mathrm{C}$ on M-S-H powders seemed to reduce the content of brucite and improved the reaction to the advantage of M-S-H. The effect appeared to be the same at $50^{\circ} \mathrm{C}$ and $70{ }^{\circ} \mathrm{C}$. Another option to quickly obtain pastes containing only M-S-H could be to use a finer silica, e.g., colloidal silica.

This paper aims to develop a protocol for producing cohesive pastes of M-S-H with high purity and different magnesium to silicon (M/S) ratios, and to microstructurally characterize them to further the knowledge on the intrinsic properties of M-S-H. Four protocols for the production of cohesive M-S-H pastes (with different M/S ratios) are proposed and compared. The two parameters modified throughout the protocols were the source of silica (silica fume and colloidal silica) and the curing temperature $\left(20^{\circ} \mathrm{C}\right.$ and $\left.50^{\circ} \mathrm{C}\right)$. Moreover, two types of mixing - mechanical and manual-were tested. The obtained M-S-H pastes were then characterized by X-ray diffraction (XRD), thermogravimetric analysis (TGA), microtomography, and energy-dispersive $X$-ray spectroscopy (EDS). The morphology of the M-S-H pastes was observed with a scanning electron microscope (SEM). Microstructure and porosity characterizations were performed by autoradiography, mercury intrusion porosimetry (MIP), water saturation and helium pycnometry. The characteristics of the pastes obtained were compared with those reported in the literature.

\section{Materials and Methods}

\subsection{Raw Materials}

M-S-H pastes were produced by mixing a source of silica (silica fume or colloidal silica), magnesium ( $\mathrm{MgO}$, to be precise) and distilled water (Milli- ${ }^{\circledR}$ water). The silica fume (CONDENSIL S95 DM), composed of $95 \% \mathrm{SiO}_{2}$ and with a specific surface of $22 \mathrm{~m}^{2} / \mathrm{g}$, was provided by Condensil ${ }^{\circledR}$. The silica fume was sieved at $315 \mu \mathrm{m}$ prior to its use in manufacturing M-S-H. The colloidal silica (Rheomac AS 150, also called Mastermatrix 150) was provided by BASF ${ }^{\circledR}$ as an aqueous suspension (dry extract $=52 \pm 2.5 \%$ ).

The magnesium was $\mathrm{MgO}$ provided by $\mathrm{VWR}^{\circledR}$ (VWR International S.A.S, 1 rue $\mathrm{d}^{\prime}$ Aurion, Rosny-sous-Bois, France), with a content of $\mathrm{MgO}$ (on the calcined product) $>97 \%$ and a loss on ignition of $8 \%$.

The superplasticizer (CHRYSO ${ }^{\circledR}$ Fluid Optima 175) was provided by Chryso France ${ }^{\circledR}$ (ZI du Sauvoy, 5 Rue de la Bizière, 77165 Saint-Soupplets, France).

\subsection{Preparation of $M-S-H$ Samples}

The M-S-H pastes were prepared according to a protocol adapted from Tonelli et al. [46]. In Tonelli's study, silica fume and $\mathrm{MgO}$ were mixed at $20^{\circ} \mathrm{C}$ with an $\mathrm{MgO} / \mathrm{SiO}_{2}(\mathrm{M} / \mathrm{S})$ atomic ratio of 1 and $a \mathrm{w} / \mathrm{b}$ ratio of 2 . In the present study, the optimal $\mathrm{w} / \mathrm{b}$ ratio (i.e., the lowest value to maintain sufficient workability without using a superplasticizer) was sought to favor a more cohesive paste, without segregation and with lower porosity. We carried out two thermal curing protocols to try to maximize the formation of M-S-H in the pastes. The source of silica was varied to accelerate the reactivity and improve the homogeneity of the mix (increasing the specific surface area of the reagents). Three different $M / S$ were selected following the work of Bernard et al. [51]: 0.78, 1 and 1.3, as detailed in Table 1. The first campaign consisted of mixes of $\mathrm{MgO}$, silica fume and Milli-Q water with $\mathrm{a} \mathrm{w} / \mathrm{b}$ of 1. For the second campaign, silica fume was replaced by colloidal silica and superplasticizer 
was used to improve the workability of the mix. Two mixing methods-mechanical (noted E; rotation speed 140-285 rd/min for $10 \mathrm{~min}, 450 \mathrm{~W}$ ) and manual (noted M; $5 \mathrm{~min}$ ) - were tested. Analysis of the chemical composition and microstructure of M-S-H pastes with different mixing techniques, $\mathrm{w} / \mathrm{b}$ ratios and therefore porosities provided a wider range of data likely comparable to M-S-H formed by precipitation in cementitious materials. All pastes with silica fume were mechanically mixed. For pastes with colloidal silica, both types of mixing were tested for every M/S. The $\mathrm{w} / \mathrm{b}$ ratio and the superplasticizer content were modified to improve the workability of the mix for manually mixed pastes $(\mathrm{w} / \mathrm{b}=1.45)$.

Table 1. Mix proportions. Sp/b represents the mass percentage of superplasticizer against binder.

\begin{tabular}{|c|c|c|c|c|c|c|c|c|c|}
\hline \multirow[b]{2}{*}{ Type of Silica } & \multirow[b]{2}{*}{$\mathbf{M} / \mathbf{S}$} & \multirow[b]{2}{*}{$\mathrm{T}\left({ }^{\circ} \mathrm{C}\right)$} & \multirow[b]{2}{*}{ Sample Name } & \multicolumn{4}{|l|}{ g } & \multirow[b]{2}{*}{$\mathrm{Sp} / \mathrm{b}$} & \multirow[b]{2}{*}{$w / b$} \\
\hline & & & & $\mathrm{MgO}$ & $\begin{array}{l}\text { Silica } \\
\text { Fume }\end{array}$ & $\begin{array}{l}\text { Milli-Q- } \\
\text { Water }\end{array}$ & $\begin{array}{l}\text { Superplasticizer } \\
\text { (Dry Extract) }\end{array}$ & & \\
\hline \multirow{3}{*}{ Silica fume } & 0.78 & $\begin{array}{l}20 \\
50\end{array}$ & $\begin{array}{l}\text { MS_0-78_SF_T20 } \\
\text { MS_0-78_SF_T50 }\end{array}$ & 176.4 & 336.9 & 513.8 & 0 & 0 & 1 \\
\hline & 1 & $\begin{array}{l}20 \\
50\end{array}$ & $\begin{array}{l}\text { MS_1_SF_T20 } \\
\text { MS_1_SF_T50 }\end{array}$ & 208.7 & 309.2 & 522.2 & 0 & 0 & 1 \\
\hline & 1.3 & $\begin{array}{l}20 \\
50\end{array}$ & $\begin{array}{l}\text { MS_1-3_SF_T20 } \\
\text { MS_1-3_SF_T50 }\end{array}$ & 242.8 & 278.1 & 526.3 & 0 & 0 & 1 \\
\hline \multirow[b]{2}{*}{ Type of Silica } & \multirow[b]{2}{*}{$\mathbf{M} / \mathbf{S}$} & \multirow[b]{2}{*}{$\mathrm{T}\left({ }^{\circ} \mathrm{C}\right)$} & \multirow[b]{2}{*}{ Sample Name } & g & & & & \multirow[b]{2}{*}{$\mathrm{Sp} / \mathrm{b}$} & \multirow[b]{2}{*}{$w / b$} \\
\hline & & & & $\mathrm{MgO}$ & $\begin{array}{l}\text { Rheomac } \\
\text { AS } 150\end{array}$ & $\begin{array}{l}\text { Milli-Q- } \\
\text { Water }\end{array}$ & $\begin{array}{l}\text { Superplasticizer } \\
\text { (Dry Extract) }\end{array}$ & & \\
\hline \multirow{6}{*}{ Colloidal silica } & 0.78 & $\begin{array}{l}20 \\
50\end{array}$ & $\begin{array}{l}\text { MS_0-78_Cs_T20_M } \\
\text { MS_0-78_Cs_T50_M }\end{array}$ & 63.2 & 241.3 & 145.8 & 8.94 & $4.9 \%$ & 1.45 \\
\hline & 0.78 & 50 & MS_0-78_Cs_T50_E & 241.1 & 920.3 & 312.5 & 47.4 & $6.8 \%$ & 1.1 \\
\hline & 1 & 50 & MS_1_Cs_T50_M & 71.7 & 213.3 & 151.5 & 9.18 & $5.1 \%$ & 1.45 \\
\hline & 1 & $\begin{array}{l}20 \\
50\end{array}$ & $\begin{array}{l}\text { MS_1_Cs_T20_E } \\
\text { MS_1_Cs_T50_E }\end{array}$ & 292.5 & 872.7 & 292.7 & 45.1 & $6.2 \%$ & 1 \\
\hline & 1.3 & $\begin{array}{l}20 \\
50\end{array}$ & $\begin{array}{l}\text { MS_1-3_Cs_T20_M } \\
\text { MS_1-3_Cs_T50_M }\end{array}$ & 119.8 & 274.3 & 235.1 & 7.14 & $2.8 \%$ & 1.45 \\
\hline & 1.3 & 50 & MS_1-3_Cs_T50_E & 331.7 & 760.8 & 403 & 38.25 & $5.4 \%$ & 1.1 \\
\hline
\end{tabular}

Two curing protocols were carried out for each type of silica and M/S ratio. Half of the samples were put in a sealed box with water (to keep relative humidity close to $100 \%$, no water bath) and placed in a climatic chamber at $50{ }^{\circ} \mathrm{C}$. The other half was put in a box with water and left at ambient temperature.

An abbreviated notation has been implemented to identify M-S-H pastes with respect to their manufacturing protocol. It begins with "MS" followed by the M/S ratio, the type of silica used (SF for silica fume and CS for colloidal silica), the temperature of curing, and finally the type of mixing (for the pastes with colloidal silica; E for mechanically mixed and $\mathrm{M}$ for manually mixed). For instance, MS_0-78_CS_T20_M matches the samples made with an $\mathrm{M} / \mathrm{S}$ ratio of 0.78 , colloidal silica, cured at ambient temperature $\left(20 \pm 2{ }^{\circ} \mathrm{C}\right)$ and mixed manually (Table 1).

\subsection{Chemical, Mineralogical and Microstructural Analysis of Pastes}

\subsubsection{Mineralogical and Chemical Analyses}

X-ray diffraction analyses were performed on powders obtained by crushing the samples, either on a Malvern Panalytical Empyrean instrument, a PANalytical X'Pert Pro operating at $40 \mathrm{kV}$ and $40 \mathrm{~mA}$ (Sorbonne Université, Jussieu, Paris, France) with a Cu anticathode $(\lambda \sim 1.54 \AA$ ) , a D8 Advance Bruker operating at $40 \mathrm{kV}$ and $40 \mathrm{~mA}$ (LMDC, Toulouse, France) with a $\mathrm{Cu}$ anti-cathode $(\lambda \sim 1.54 \AA)$, or a PANalytical Aeris (IRSN, Fontenay-auxRoses, France) operating at $600 \mathrm{~W}, 40 \mathrm{kV}$ and $15 \mathrm{~mA}$, with a Cu anti-cathode $(\lambda \sim 1.54 \AA$ ). The scanning region was in the range $2 \Theta=5^{\circ}-70^{\circ}$ with either: (i) a step size of 0.0131 , for a total duration of $4 \mathrm{~h}$ (Jussieu, Paris, France); (ii) a step size of 0.020 , for a total duration 
of $2 \mathrm{~h}$ (LMDC, Toulouse); or (iii) a step size of 0.0109 , for a total duration of $20 \mathrm{~min}$ (IRSN, Fontenay-aux-Roses, France). X-ray diffractograms were plotted against the $2 \Theta$ angle, noted $[2 \Theta] \mathrm{CuK} \alpha$. Table 2 lists the instruments used for each sample analyzed.

Table 2. Protocol used on samples in X-ray diffraction.

\begin{tabular}{|c|c|c|}
\hline Sample Name & Location of Test & Protocol \\
\hline MS_0-78_SF_T20_19d & Sorbonne Université & PANalytical X’Pert Pro (PANalytical \\
\hline MS_0-78_SF_T50_19d & Sorbonne Université & Empyrean instrument) operating at $40 \mathrm{kV}$ \\
\hline MS_0-78_Cs_T20_16d & Sorbonne Université & and $40 \mathrm{~mA}$ with a $\mathrm{Cu}$ anti-cathode $(\lambda \sim 1.54 \AA)$ \\
\hline MS_0-78_Cs_T50_16d & Sorbonne Université & \\
\hline MS_1_SF_T20_91d & Sorbonne Université & $2 \Theta=5^{\circ}-70^{\circ}$ with a step size of 0.0131 , for a \\
\hline MS_1-3_SF_T20_91d & Sorbonne Université & \\
\hline Colloidal silica & LMDC & \\
\hline Silica fume & IRSN & \\
\hline MS_1_SF_T20_19d & IRSN & \\
\hline MS_1-3_SF_T20_19d & IRSN & PANalytical Aeris operating at $600 \mathrm{~W}$, \\
\hline MS_1_SF_T50_19d & IRSN & $40 \mathrm{kV}$ and $15 \mathrm{~mA}$, \\
\hline MS_1-3_SF_T50_19d & IRSN & with a $\mathrm{Cu}$ anti-cathode $(\lambda \sim 1.54 \AA)$, \\
\hline MS_0-78_Cs_T50_128d & IRSN & step size of 0.0109 , for a total duration of \\
\hline MS_1_Cs_T50_156d & IRSN & $20 \mathrm{~min}$ \\
\hline MS_1-3_Cs_T50_122d & IRSN & \\
\hline
\end{tabular}

Thermogravimetric analyses were carried out under argon flux on non-dried powdered M-S-H samples (30-40 mg) with a Mettler TGA 2 instrument (LMDC, Toulouse, France) and a heating rate of $10^{\circ} \mathrm{C} / \mathrm{min}$ from ambient temperature to $980^{\circ} \mathrm{C}$. The powders used for the test were obtained by crushing a cross section of the sample to $80 \mu \mathrm{m}$. The amount of $\mathrm{Mg}(\mathrm{OH})_{2}$ was quantified from the weight loss around $420^{\circ} \mathrm{C}\left(335-455{ }^{\circ} \mathrm{C}\right)$ using the stepwise method [52] and calculated according to Equation (1):

$$
\mathrm{wt}^{\mathrm{o}} \mathrm{\text {brucite } _ { \mathrm { dry } }}=\frac{\text { water loss }(\text { brucite })}{100-\text { water } \operatorname{loss}_{\mathrm{H}_{2} \mathrm{O}\left(25-550{ }^{\circ} \mathrm{C}\right)}} \times \frac{\mathrm{M}_{\text {brucite }}}{\mathrm{M}_{\mathrm{H}_{2} \mathrm{O}}} \times 100
$$

where $w \mathrm{t} \%$ brucite $_{\text {dry }}$ corresponds to the weight percentage of brucite for $100 \mathrm{~g}$ of dry mass $(\mathrm{g} / 100 \mathrm{~g})$ and water losses are expressed in weight percentages. $\mathrm{M}_{\text {brucite }}$ is the molar mass of $\mathrm{Mg}(\mathrm{OH})_{2}$ (equal to $58.32 \mathrm{~g} / \mathrm{mol}$ ) and $\mathrm{M}_{\mathrm{H} 2 \mathrm{O}}$ is the molar mass of water (equal to $18.02 \mathrm{~g} / \mathrm{mol})$. The relative error on the brucite content was $\pm 5-10 \%$ [52].

Solid chemical characterizations were carried out with an energy-dispersive spectrometry (EDS) system adapted to a scanning electron microscope (SEM; Hitachi S3500N, IRSN, Fontenay-aux-Roses, France). The system comprised two EDS Brücker SDD detectors working at $15 \mathrm{kV}$ and a working distance of $16.8 \mathrm{~mm}$. Observations were performed on a polished section (Protocol in Appendix A, Table A1) coated with a gold-palladium alloy (277 Å thick).

Microscopic imagery was carried out with the same instrument on fractures coated with a thin gold-palladium layer (92 $\AA$ thick) at $25 \mathrm{kV}$. The working distance depended on the sample and its geometry.

\subsubsection{Microstructure Analyses}

Different types of microstructure analyses were conducted. Figure 1 illustrates the porosity characterization techniques used as a function of pore range associated with the dimensional range of solids and pores in hydrated cement and M-S-H pastes. The porosity characterization of the pastes was carried out by combining several techniques. Pore distribution from $2.5 \mathrm{~nm}$ to $0.1 \mathrm{~mm}$ was determined by nitrogen physisorption and MIP. The open porosity of the samples was measured by autoradiography, $\operatorname{MIP}\left(\Phi_{\mathrm{M}}\right)$, saturation of the material with water $\left(\Phi_{\mathrm{W}}\right)$, and by means of a calculation $\left(\Phi_{\mathrm{H}}\right)$ from the bulk $\left(\rho_{\text {bulk }}\right)$ 
and true densities $\left(\rho_{\text {true }}\right)$. X-ray microtomography was used to observe the distribution of unreacted silica particles in the pastes.

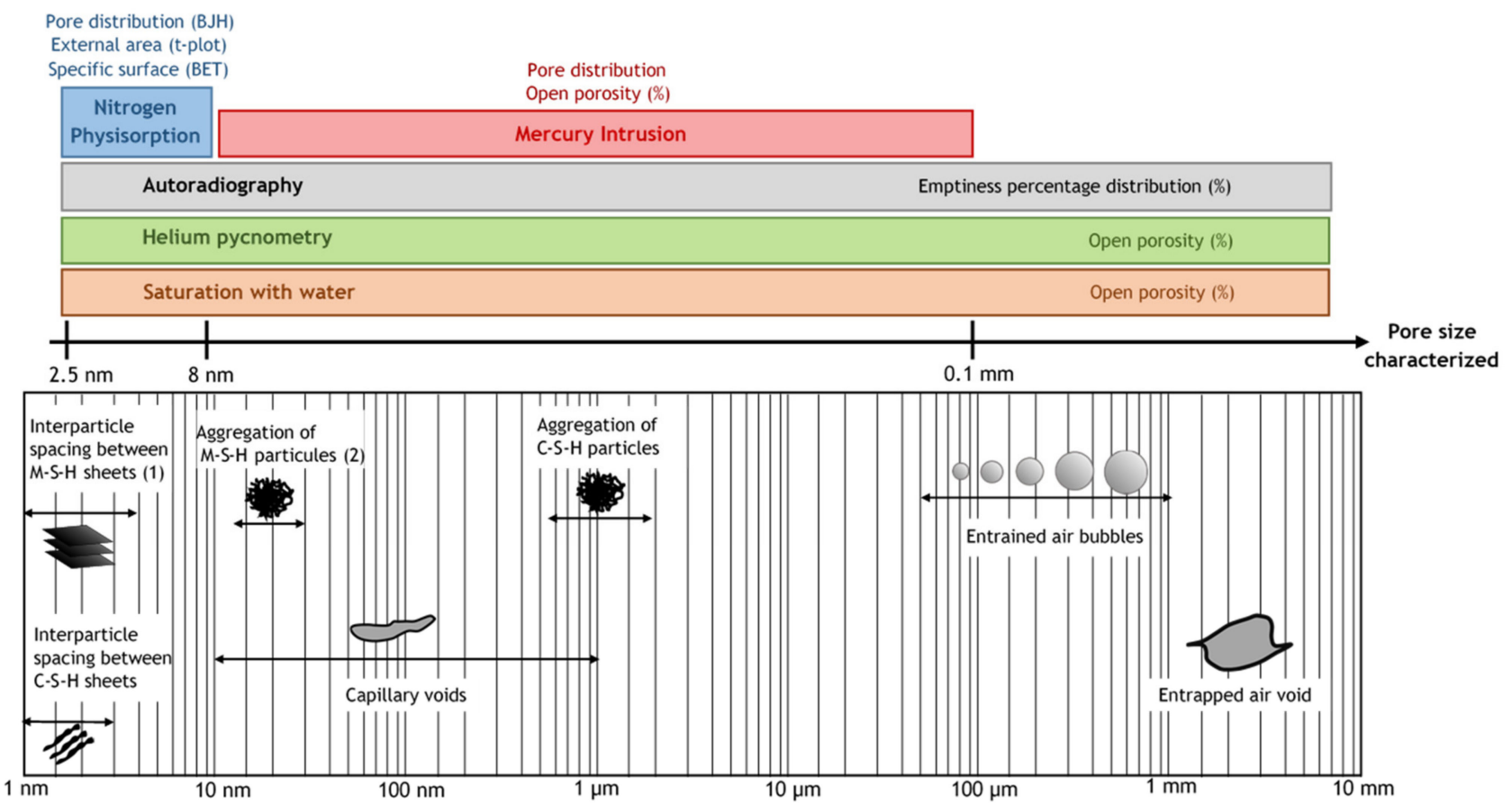

Figure 1. Representation of porosity characterization techniques as a function of pore range associated with the dimensional range of solids and pores in an M-S-H paste (adapted from Mehta and Monteiro [53]). (1) After Bernard [43] and (2) after Tonelli [46].

M-S-H samples were analyzed by X-ray microtomography using two different devices: SkyScan 1272 and SkyScan 1173 (Bruker microCT N.V, Fontenay-aux-Roses, France). A spatial resolution of $15 \mu \mathrm{m}$ was obtained for a sample size of approximately $5 \mathrm{~cm}^{3}$. The parameters of the X-ray tube $(100 \mathrm{kV}, 100 \mathrm{~mA})$ were set to optimize the contrast between the different phases and the pores. An angular step of $0.3^{\circ}$ was used to acquire radiographs (total acquisition time of approximately $9 \mathrm{~h}$ ).

Autoradiographic analyses were conducted on $1.5 \mathrm{~cm} \times 1.5 \mathrm{~cm} \times 2 \mathrm{~cm}$ samples made from colloidal silica. Samples were impregnated with C-14-methylmethacrylate (C-14MMA) tracer solution, filling the connected porosity. The polymerization process was induced by gamma irradiation in order to fix the tracer to the open pore space. Samples were cut, polished and exposed on storage phosphor imaging plates (IPs) for 1-3 days. After exposure, the IPs were scanned using a FUJI-FLA 5100 digital scanner with a resolution of 1200 dpi and a 16-bit image depth to obtain the autoradiographs of the impregnated samples. The scanning resolution of the film was $10 \mu \mathrm{m}$. Quantification of porosity is based on the assumption that optical densities on autoradiographs are proportional to the content of the decaying tracer isotope in the material [54-58]. First, the optical densities of the autoradiographs are calculated. All intensity values or grey levels in the subdomains (pixels) are converted into the corresponding optical densities, which in turn are converted into activities with calibration curves measured for each exposure. Finally, the activities are converted into porosities by taking into account the beta attenuation and the true density of the samples (measured by helium pycnometry) [57]. Several PMMA standards of known C-14 activities are needed to convert the grey values of each pixel into porosity values [57-60]. The uncertainty of the C-14-PMMA autoradiography has been empirically determined to be approximately 10\% [57]. Three samples with colloidal silica-one for every $\mathrm{M} / \mathrm{S}$ - were analyzed of which one broke during impregnation $(\mathrm{M} / \mathrm{S}=1)$, making it impossible to analyze this ratio. The sample with $\mathrm{M} / \mathrm{S}=1.3$ was divided into two parts, allowing for two analyses. 
Nitrogen sorption isotherms were measured using a Micromeritics 3Flex 3500 (Norcross, GA, USA) instrument equipped with version 4.05 of the 3Flex software (IRSN, Fontenay-aux-Roses). Prior to the analysis, the samples were reduced into pieces of approximately $0.2 \mathrm{~cm}^{3}$ and placed in a freeze dryer (Crios-50, Cryotec, IRSN, Fontenay-aux-Roses, France) for a least 5 days. They were then degassed (i.e., heated at $45^{\circ} \mathrm{C}$ under a vacuum in a sample cell) in the instrument for $4 \mathrm{~h}$ to remove water and other physically adsorbed volatile material from the surface of the sample. The samples underwent nitrogen adsorption and desorption for approximately $20 \mathrm{~h}$. Three measurements were carried out on each sample. The specific surface area $\left(\mathrm{SSA}_{\mathrm{BET}}\right)$ of the samples was calculated by applying the Brunauer-Emmett-Teller (BET) equation in the $\mathrm{p} / \mathrm{p}^{0}$ range $0.05-0.2$. External surface area $\left(\mathrm{SSA}_{\text {ext }}\right)$ and total pore volume were calculated from the $\mathrm{t}$-curve (obtained from the equations fitted on Aerosil 200 in [61]) for $\mathrm{p} / \mathrm{p}^{0}<0.8$, between 7 and $10 \AA$ on the second slope [61,62]. Figure 2 illustrates the $t$-curve of one sample with the slopes and calculation parameters. $\mathrm{SSA}_{\text {meso }}+$ ext corresponds to the mesopore + external surface areas and to the $S_{S A}$. The pore distribution was obtained with the Barrett-Joyner-Halenda (BJH) method [63].

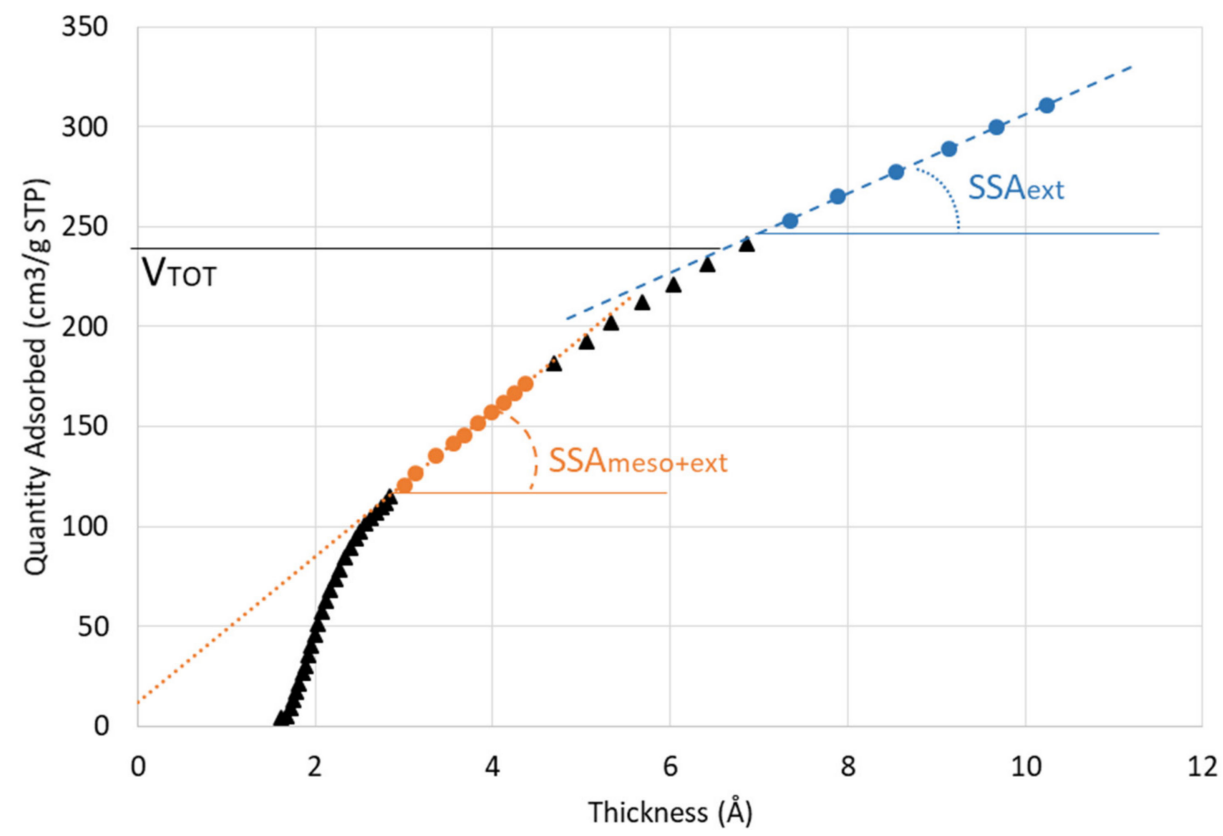

Figure 2. Illustration of the t-plot on an M-S-H paste highlighting the external surface area $\left(\mathrm{SSA}_{\mathrm{ext}}\right)$, the pore volume $\left(\mathrm{V}_{\mathrm{TOT}}\right)$, and the total specific surface area $\left(\mathrm{SSA}_{\text {meso }}+\mathrm{ext}\right)$, which corresponds to the specific surface area calculated with BET (after Galarneau et al. [61]).

Mercury intrusion porosimetry was performed with an AutoPore IV 9500 porosimeter from Micromeritics (LMDC, Toulouse, France). The samples underwent the same pretreatment as for nitrogen physisorption. After a pre-equilibrium step to fill the gaps between the sample and the chamber wall at $3 \mathrm{KPa}$, the pressures on mercury were automatically and stepwise raised to $413.69 \mathrm{MPa}$.

The determination of bulk densities $\left(\rho_{\text {bulk }}\right)$ was performed by measuring the pressure induced through the immersion of the sample in kerosene according to Archimedes' principle, following the method initially proposed by Monnier et al. [64] and included in the AFNOR standard X31-505 [65]. The samples remained $4 \mathrm{~h}$ in kerosene before weighing.

Water content measurements were carried out at IRSN by weighing before and after heating at $105^{\circ} \mathrm{C}$ until constant weight was reached. The water absorption of samples was 
determined by immersion in Milli-Q water for $24 \mathrm{~h}$ followed by heating at $105^{\circ} \mathrm{C}$ until constant weight was reached. The open porosity $\left(\phi_{w}\right)$ was determined with Equation (2):

$$
\phi_{\mathrm{W}}=\frac{\mathrm{m}_{\mathrm{water}}}{\mathrm{m}_{\mathrm{total}}} \times \frac{\rho_{\text {bulk }}}{\rho_{\mathrm{water}}}
$$

where $\rho_{\text {bulk }}$ is the bulk density of the material, $\rho_{\text {water }}=1 \mathrm{~g} / \mathrm{cm}^{3}, \mathrm{~m}_{\text {water }}$ is the mass of water in the saturated sample and $\mathrm{m}_{\text {total }}$ is the total mass of the sample after heating at $105^{\circ} \mathrm{C}$.

A pycnometer (Micrometrics, AccuPyc II 1340, IRSN, Fontenay-aux-Roses, France) was used to determine the true density $\left(\rho_{\text {true }}\right)$ of the samples. The volume of the samples of known mass was determined from the pressure change of helium in a calibrated volume. Measurements were performed in $10 \mathrm{~cm}^{3}$ modules on a set of pieces of $0.2 \mathrm{~cm}^{3}$. Fifteen cycles of introduction and extraction of helium were operated. The open porosity $\left(\phi_{\mathrm{H}}\right)$ was calculated with Equation (3):

$$
\phi_{\mathrm{H}}=1-\frac{\rho_{\text {bulk }}}{\rho_{\text {true }}}
$$

where $\rho_{\text {bulk }}$ is the bulk density of the material and $\rho_{\text {true }}$ is the true density of the material.

\section{Chemical and Microstructural Characterization of M-S-H as a Function of Design and Curing Protocols}

\subsection{Influence of the Type of Silica}

Images of $X$-ray microtomography analyses (Figure 3) and EDS mappings (Figures 4 and 5) showed that switching the silica source from silica fume to colloidal silica resulted in a better distribution of the particles and a higher homogeneity of the hydrated paste, irrespective of the curing temperature.
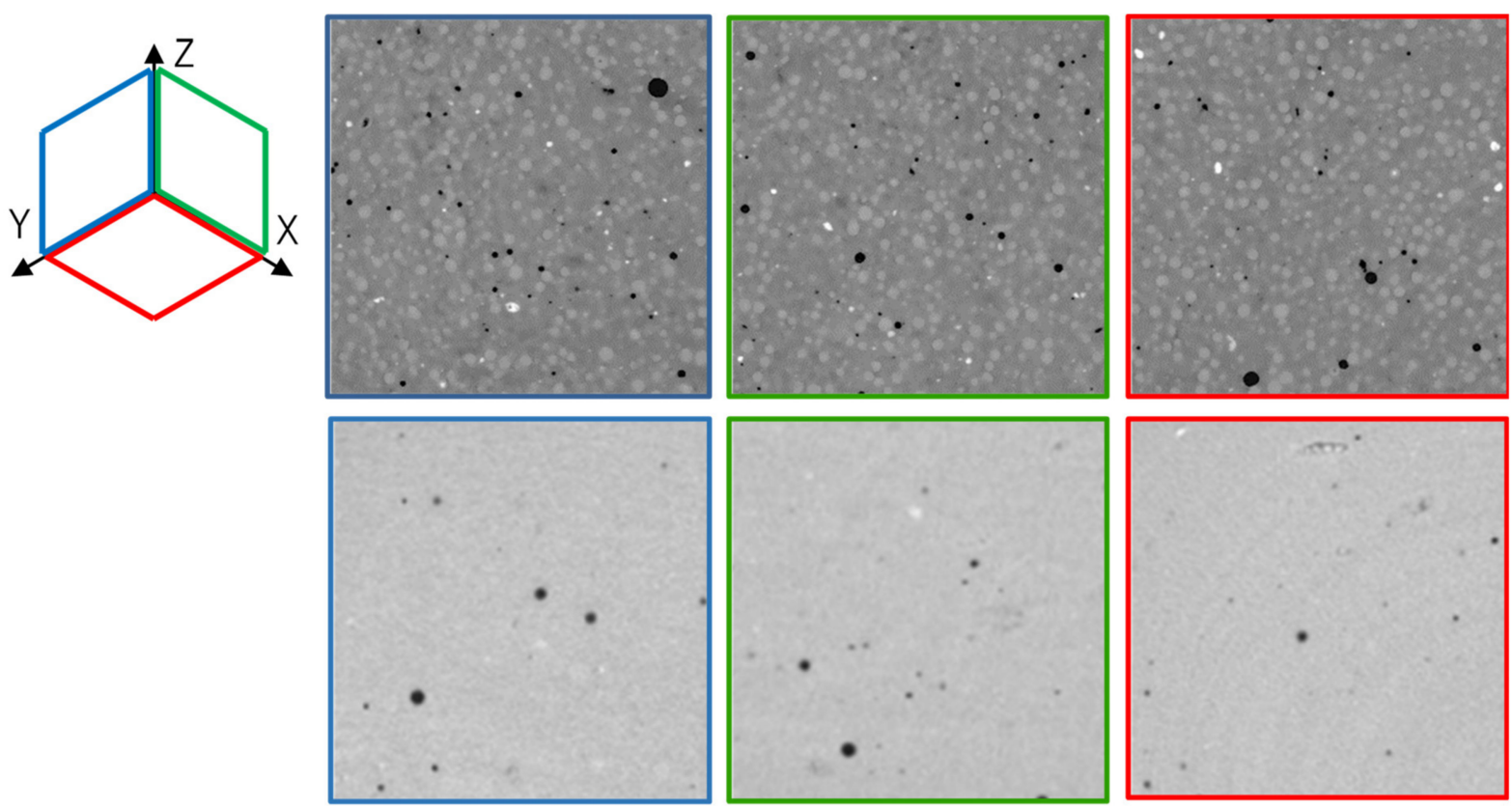

Figure 3. Tomography images: MS_1_SF_T50_21d (top) and MS_1_Cs_T20_3d (bottom). 


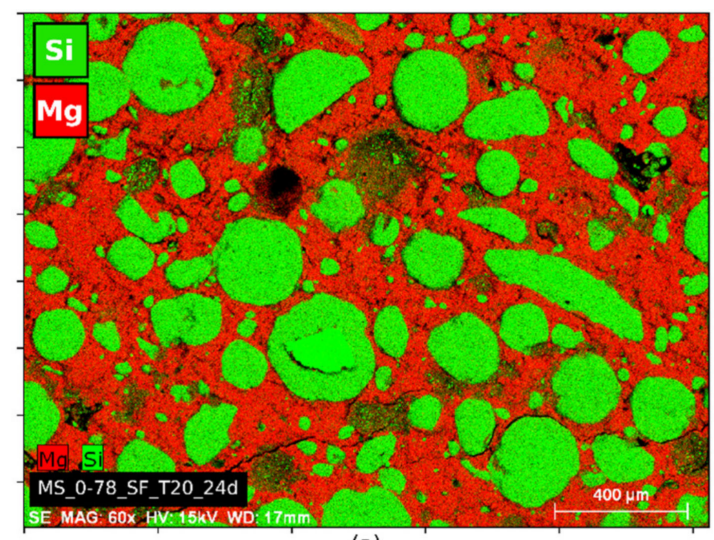

(a)

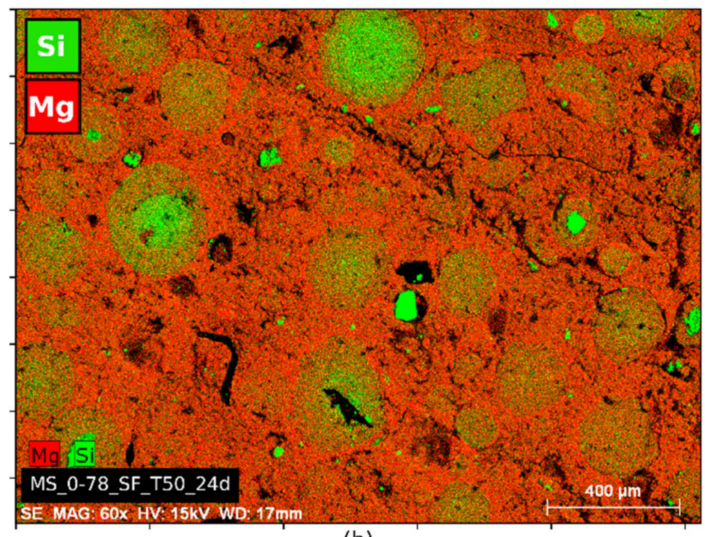

(b)

Figure 4. EDS images of M-S-H pastes with $\mathrm{M} / \mathrm{S}=0.78$ and silica fume after 24 days of hydration. (a) curing at $20^{\circ} \mathrm{C} ;\left(\right.$ b) curing at $50{ }^{\circ} \mathrm{C}$.

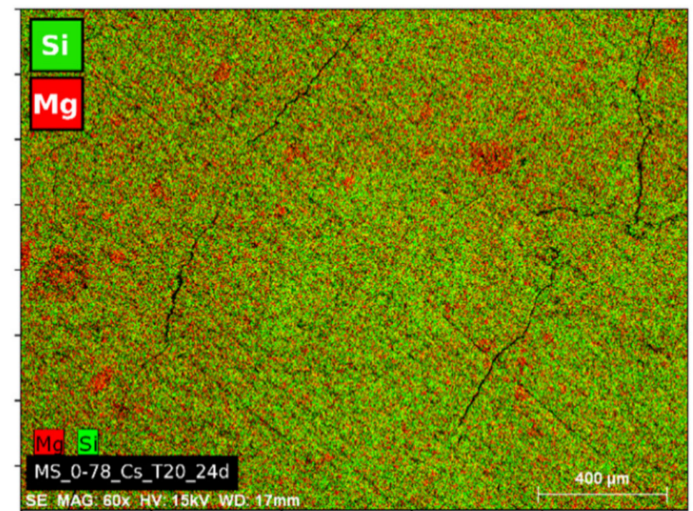

(a)

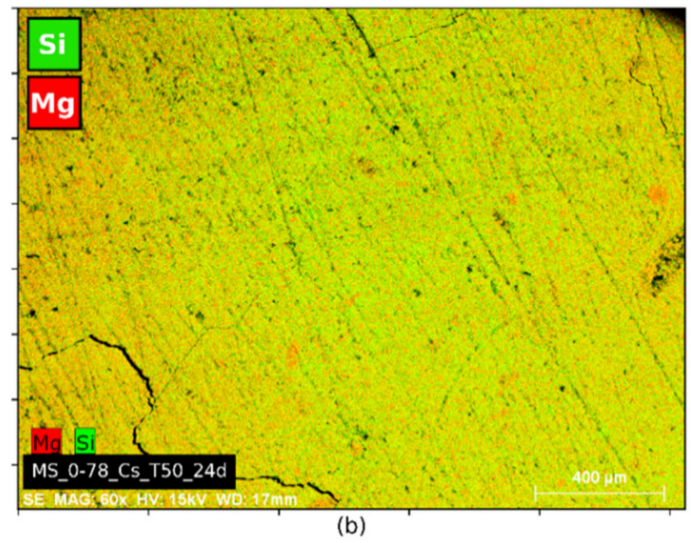

(b)

Figure 5. EDS images of M-S-H pastes with M/S $=0.78$ and colloidal silica after 24 days of hydration. (a) curing at $20^{\circ} \mathrm{C} ;\left(\right.$ b) curing at $50{ }^{\circ} \mathrm{C}$.

EDS mappings (Figures 4 and 5) obtained from the pastes cured at $20^{\circ} \mathrm{C}$ show the effect of the silica type on the size of the cluster of unreacted silica. The average cluster size was $200 \mu \mathrm{m}$ for silica fume and $25 \mu \mathrm{m}$ for colloidal silica. The latter resulted in a better dispersion of silica particles within the Mg-matrix, improving the homogeneity of the paste (even if this distribution does not allow to evaluate whether the dispersed silica has already reacted with $\mathrm{MgO}$ ).

Furthermore, the raw colloidal silica did not contain crystallized phases (such as quartz or cristobalite) but only amorphous silica. This was confirmed by the absence of the corresponding peaks (Table 3) on the X-ray diffractograms of colloidal silica pastes (Figure $6 \mathrm{~b}$ ), although quartz peaks were observed on the X-ray diffractograms of silica fume pastes (Figure 6a).

In conclusion, the use of colloidal silica led to improved homogeneity and purity, i.e., in terms of presence of M-S-H only, of the pastes. 
Table 3. Indexing of X-ray peaks for quartz, cristobalite, brucite, amorphous silica, and M-S-H.

\begin{tabular}{|c|c|c|c|c|c|c|c|c|}
\hline References & Species & Unit & \multicolumn{6}{|c|}{ Peaks Indexing } \\
\hline $\begin{array}{l}\text { COD 96-901-0145 and } \\
\text { COD 96-900-9687 }\end{array}$ & $\begin{array}{l}\text { Quartz and } \\
\text { cristobalite }\end{array}$ & $\begin{array}{c}\AA \\
{[2 \Theta] \mathrm{CuK} \alpha}\end{array}$ & $\begin{array}{l}4.26 \\
20.85\end{array}$ & $\begin{array}{l}4.05 \\
21.92\end{array}$ & $\begin{array}{l}3.34 \\
26.65\end{array}$ & $\begin{array}{l}3.14 \\
28.39\end{array}$ & & \\
\hline Bernard et al. [36] & Brucite & $\begin{array}{c}\AA \\
{[2 \Theta] \mathrm{CuK} \alpha}\end{array}$ & $\begin{array}{l}4.76 \\
18.6\end{array}$ & $\begin{array}{l}2.74 \\
32.7\end{array}$ & $\begin{array}{c}2.37 \\
38\end{array}$ & $\begin{array}{l}1.79 \\
50.9\end{array}$ & $\begin{array}{l}1.57 \\
58.7\end{array}$ & $\begin{array}{c}1.50 \\
62\end{array}$ \\
\hline Data of Figure 4 & $\begin{array}{c}\text { Amorphous } \\
\text { silica }\end{array}$ & $\begin{array}{c}\AA \\
{[2 \Theta] \mathrm{CuK} \alpha}\end{array}$ & $\begin{array}{c}4.04 \\
22\end{array}$ & & & & & \\
\hline $\begin{array}{l}\text { Bernard et al. [43] and } \\
\text { Roosz et al. [33] }\end{array}$ & M-S-H & $\begin{array}{c}\AA \\
{[2 \Theta] \mathrm{CuK} \alpha}\end{array}$ & $\begin{array}{c}4.43 \\
20\end{array}$ & $\begin{array}{c}3.42 \\
26\end{array}$ & $\begin{array}{c}2.56 \\
35\end{array}$ & $\begin{array}{c}1.70 \\
54\end{array}$ & $\begin{array}{c}1.54 \\
60\end{array}$ & \\
\hline
\end{tabular}

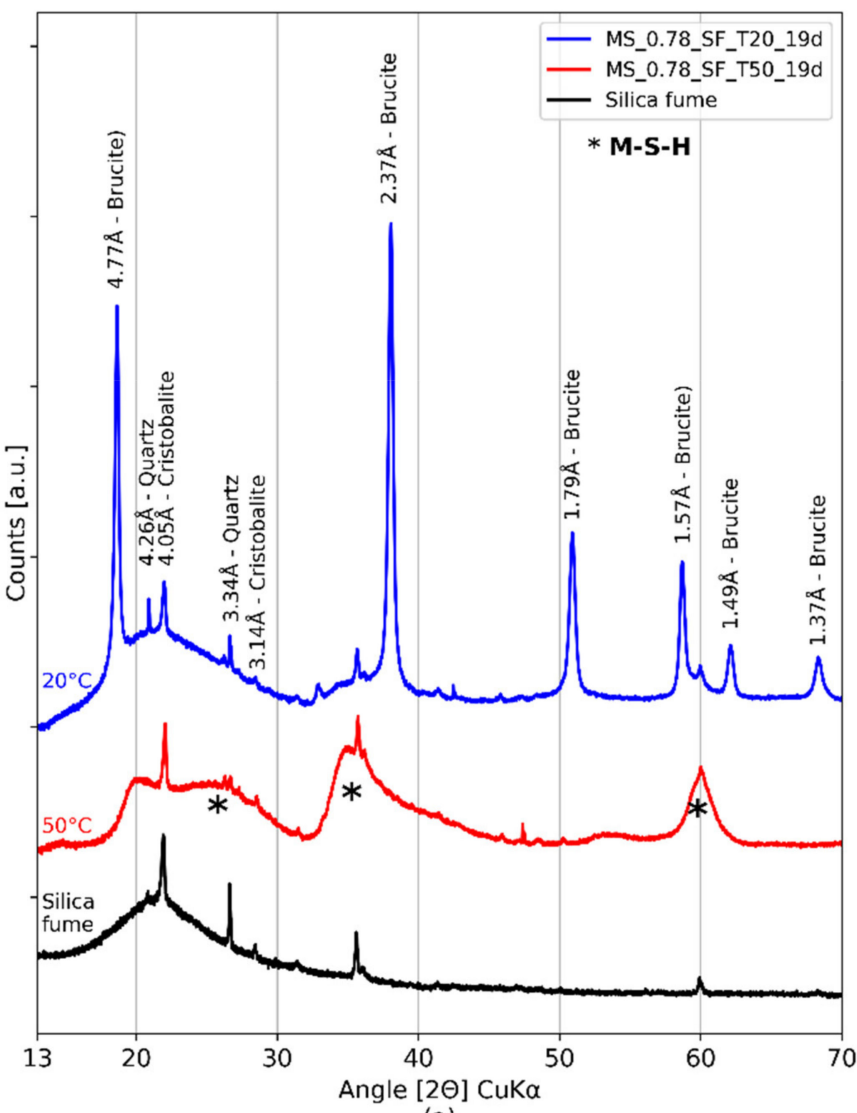

(a)

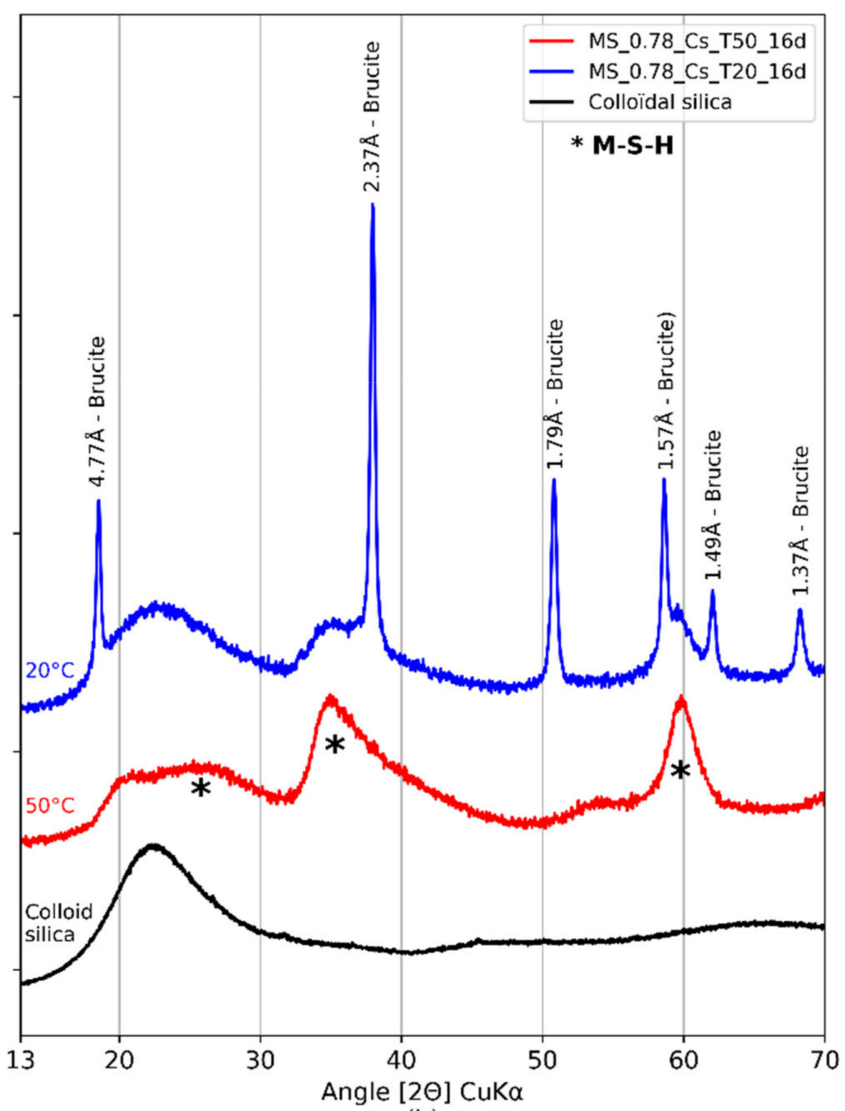

(b)

Figure 6. X-ray diffractograms of M-S-H pastes with $M / S=0.78$. Comparison between the four protocols after two weeks of hydration. (a) Pastes with silica fume and M/S $=0.78$ after 19 days of hydration at $20^{\circ} \mathrm{C}$ (blue) or $50^{\circ} \mathrm{C}$ (red) (b) Pastes with colloidal silica and M/S $=0.78$ after 16 days of hydration at $20^{\circ} \mathrm{C}$ (blue) or $50{ }^{\circ} \mathrm{C}$ (red).

\subsection{Influence of the Curing Temperature}

Pastes prepared with silica fume. Mg and Si EDS mapping of M-S-H pastes with $\mathrm{M} / \mathrm{S}=0.78$ and silica fume are shown in Figure 4 . The samples used for the tests originated from the same mix and were cured for 24 days at $20^{\circ} \mathrm{C}$ or $50{ }^{\circ} \mathrm{C}$.

Areas rich in silicon and poor in magnesium were observed for the $20{ }^{\circ} \mathrm{C}$ curing (Figure 4a). These areas correspond to residual unreacted silica fume clusters. At this temperature, the reaction of $\mathrm{MgO}$ with silica fume was slow and did not result in a homogeneous M-S-H paste at the time of observation. At $50{ }^{\circ} \mathrm{C}$ (Figure $4 \mathrm{~b}$ ), orange regions on the mapping correspond to a mix of $\mathrm{Mg}$ - and Si-containing phases, with an equivalent intensity of these elements. The matrix was enriched in silicon and the remains of the 
clusters were enriched in magnesium. This paste was more homogeneous than the paste cured at $20^{\circ} \mathrm{C}$.

In order to evaluate the mineralogical composition of the paste, XRD (Figure 6a) analyses were performed.

The sample cured at $20^{\circ} \mathrm{C}$ contained brucite and amorphous silica (Figure 6a). The presence of M-S-H was detected but their formation was likely limited by the initial formation of brucite, at least at the tested ages [34,43]. For the $50{ }^{\circ} \mathrm{C}$ curing, no characteristic peak of brucite was visible and the amorphous silica seemed to have been consumed (the associated hump disappeared). Conversely, M-S-H humps were clearly observable (as M-S-H are a semi-amorphous phase, only broad peaks or humps are observed). The five M-S-H humps observed by Bernard et al. and Roosz et al. [33,43], including three main humps $[32,46,66](\sim 20,26,35,54,60[2 \Theta] \mathrm{CuK} \alpha)$ were present in the sample cured at $50{ }^{\circ} \mathrm{C}$. The same observations were made for the other M/S pastes tested in the present study.

Pastes prepared with colloidal silica. Mg and Si EDS mapping of M-S-H pastes with $\mathrm{M} / \mathrm{S}=0.78$ and colloidal silica are shown in Figure 5. As for the sample with silica fume, brucite was visible on X-ray diffractograms after 16 days of $20^{\circ} \mathrm{C}$ curing (Figure 6b) while only M-S-H humps were present at $50{ }^{\circ} \mathrm{C}$. The pastes with colloidal silica considered for this analysis were mechanically mixed, except for $M / S=1$ for practical reasons (not produced at the same time). EDS mapping (Figure 5a,b) showed a better distribution of magnesium and silicon in the paste cured at $50{ }^{\circ} \mathrm{C}$ than in the paste cured at $20^{\circ} \mathrm{C}$. The clusters observed at $20{ }^{\circ} \mathrm{C}$ were reduced considerably at $50{ }^{\circ} \mathrm{C}$, dropping from a diameter of $25 \mu \mathrm{m}$ to a few microns.

In conclusion, the thermal curing at $50{ }^{\circ} \mathrm{C}$ resulted in a more homogeneous paste. Pastes showed a lower content of brucite at this temperature than pastes cured at $20^{\circ} \mathrm{C}$. No brucite was observed for the pastes with an $\mathrm{M} / \mathrm{S}$ ratio equal to 0.78 , even after only 16 days of curing for pastes designed with colloidal silica (Figure $6 \mathrm{~b}$ ).

To produce M-S-H with different $\mathrm{M} / \mathrm{S}$ ratios, with properties comparable to those observed in synthesis (on powders) $[32,33,43]$ and with the highest content of M-S-H and the lowest content of impurities, the suggested method is a protocol with colloidal silica and $50{ }^{\circ} \mathrm{C}$ thermal curing.

\subsection{Formation of $M-S-H$}

The kinetics of M-S-H formation at $20^{\circ} \mathrm{C}, 50^{\circ} \mathrm{C}$ and $70{ }^{\circ} \mathrm{C}$ have been studied on M-S-H powders by Bernard [51]. The purpose of this section is to compare the observations and conclusions between powders and pastes. The phenomena and kinetics of diffusion of ionic species-and the accessibility to water for reagents through already formed hydrate layers-are different between powders and cohesive pastes. Bernard et al. produced M-S-H powders by mixing magnesium oxide and silica fume with ultrapure water (water/solid ratio of 45$)[43,51]$. Figure 7 presents X-ray diffractograms of M-S-H pastes made with silica fume with $\mathrm{M} / \mathrm{S}=1$ and $\mathrm{M} / \mathrm{S}=1.3$ after 19 and 91 days of curing at $20{ }^{\circ} \mathrm{C}$ or $50{ }^{\circ} \mathrm{C}$.

The precipitation of brucite was not impeded by curing at $50^{\circ} \mathrm{C}$ for the two sources of silica. Brucite was observed on the XRD for $\mathrm{M} / \mathrm{S}=1.3$ after 19 days of hydration at $50{ }^{\circ} \mathrm{C}$ (silica fume; Figure 7c). In addition, the M/S ratio seemed to influence the persistence of brucite. The higher the ratio, the longer the brucite remained present. Brucite was observed for high $(\mathrm{M} / \mathrm{S}=1.3)$ but not low $(\mathrm{M} / \mathrm{S} \leq 1) \mathrm{M} / \mathrm{S}$ ratios after either 19 days of thermal curing at $50{ }^{\circ} \mathrm{C}$ or 91 days at $20^{\circ} \mathrm{C}$ (Figure 7 ).

This result was in agreement with the observations of Bernard on M-S-H powders [51]. In that study, no brucite was observed in M-S-H powders at $\mathrm{M} / \mathrm{S}<1.0$ cured at $50{ }^{\circ} \mathrm{C}$ or $70{ }^{\circ} \mathrm{C}$ after the same hydration time (91 days), while at $20^{\circ} \mathrm{C}$ some brucite was observed, indicating a faster formation of M-S-H at higher temperatures. For M/S $\geq 1.2$, brucite was still observed even after one year at $50{ }^{\circ} \mathrm{C}$ and $70{ }^{\circ} \mathrm{C}$. The presence of residual brucite was thus linked to the $\mathrm{M} / \mathrm{S}$ ratio. The higher the $\mathrm{M} / \mathrm{S}$ ratio, the longer the presence of brucite. It should be noted that TGA on pastes with colloidal silica no longer showed the presence 
of brucite after 5 months for all the M/S ratios in the present study. This result is presented in Section 4.2.

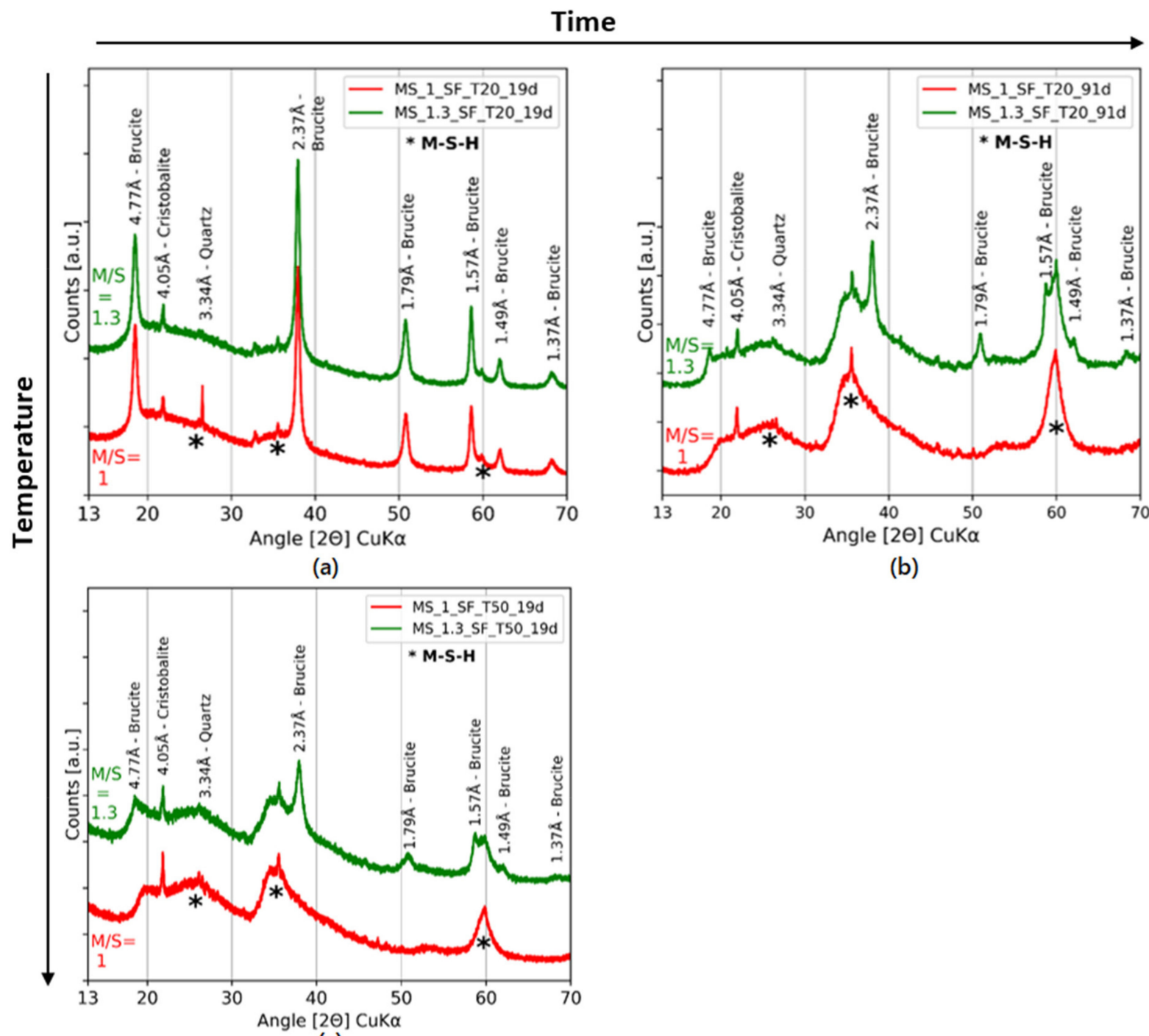

(c)

Figure 7. X-ray diffractograms of pastes with silica fume after 19 (a) or 91 days (b) with $20^{\circ} \mathrm{C}$ curing, and with $50{ }^{\circ} \mathrm{C}$ curing after 19 days (c).

The effect of thermal curing could be twofold in that it may: (i) accelerate the dissolution of $\mathrm{SiO}_{2}$ and $\mathrm{MgO}$ and the diffusion of ionic species, and (ii) shift thermodynamic equilibria. Bernard [51] stated that temperature had a significant influence on the kinetics of M-S-H formation and their solubility, having observed a faster M-S-H formation at higher temperatures. The magnesium and silicon concentrations at $50{ }^{\circ} \mathrm{C}$ and $70{ }^{\circ} \mathrm{C}$ reached equilibrium with $\mathrm{M}-\mathrm{S}-\mathrm{H}$ faster than at $20^{\circ} \mathrm{C}$. According to Bernard's work, the thermodynamic equilibrium of brucite was modified with the curing temperature. More $\mathrm{Mg}$ was needed in solution at $50{ }^{\circ} \mathrm{C}$ than at $20{ }^{\circ} \mathrm{C}$ to form brucite. Brucite only formed in the short term for lowM/S ratios with $\mathrm{SiO}_{2}$ dissolving and diffusing over time. The ratio in solution decreased, becoming more favorable to $\mathrm{M}-\mathrm{S}-\mathrm{H}$ and less to brucite (which dissolved).

In conclusion, the formation of $\mathrm{M}-\mathrm{S}-\mathrm{H}$ pastes from $\mathrm{MgO}$ and $\mathrm{SiO}_{2}$ (silica fume or colloidal silica) is a slow process that can be accelerated by thermal curing. As expected, the higher the $M / S$ ratio, the longer the brucite is present. 


\section{In-Depth Characterization of Colloidal Silica M-S-H Pastes with Different M/S Ratios}

As detailed in the previous section, the protocol with colloidal silica and a $50{ }^{\circ} \mathrm{C}$ curing yielded the highest content of M-S-H and the lowest content of other species. In this section, the samples analyzed originate from this protocol exclusively. Two types of mixing were tested, mechanical and manual. Three M/S ratios were studied: $0.78,1$ and 1.3. The pastes considered for Sections 4.1 and 4.2 were MS_0-78_CS_T50_M, MS_1_CS_T50_E and MS_1-3_CS_T50_M.

\subsection{Morphology of $\mathrm{M}-\mathrm{S}-\mathrm{H}$}

The morphology of M-S-H pastes was observed by SEM on fractured samples (Figure 8), proving to be similar to the morphology reported by Tonelli et al. [46]. M-S-H did not show crystalline facies but rather aspects of gel with globular chains. M-S-H showed high porosity at high magnification (Figure 8c), as we will discuss in Section 4.3.

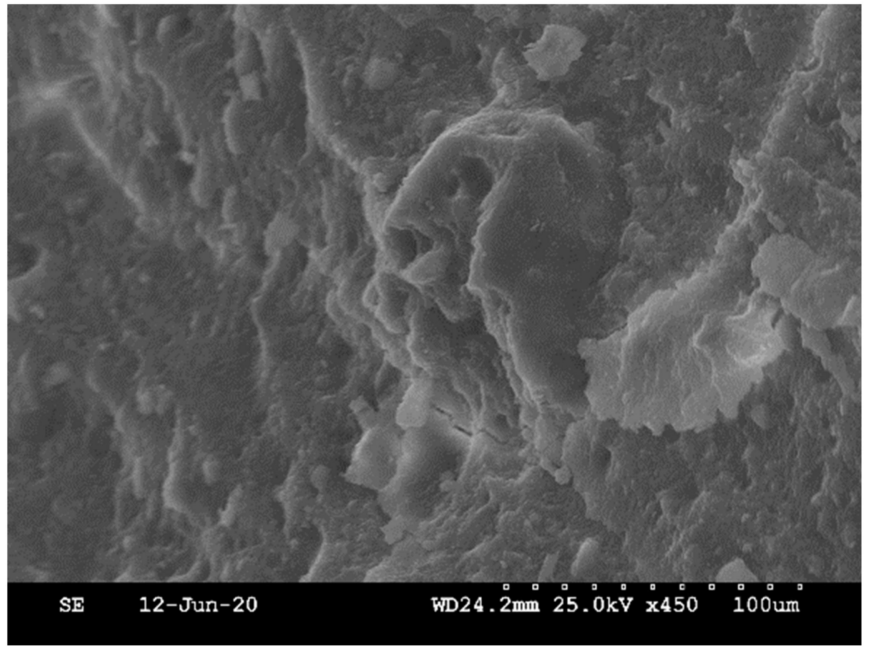

(a)

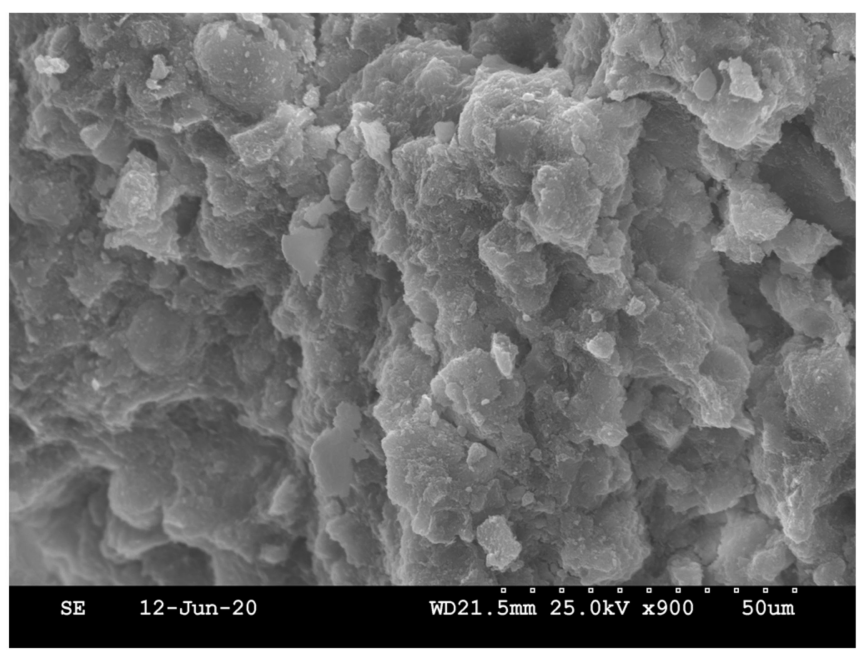

(c)

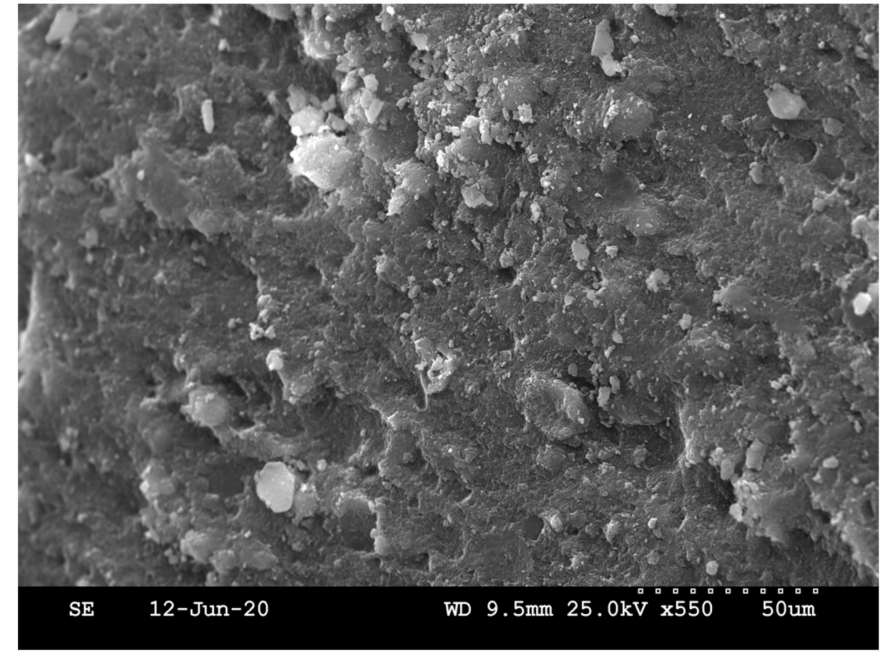

(b)

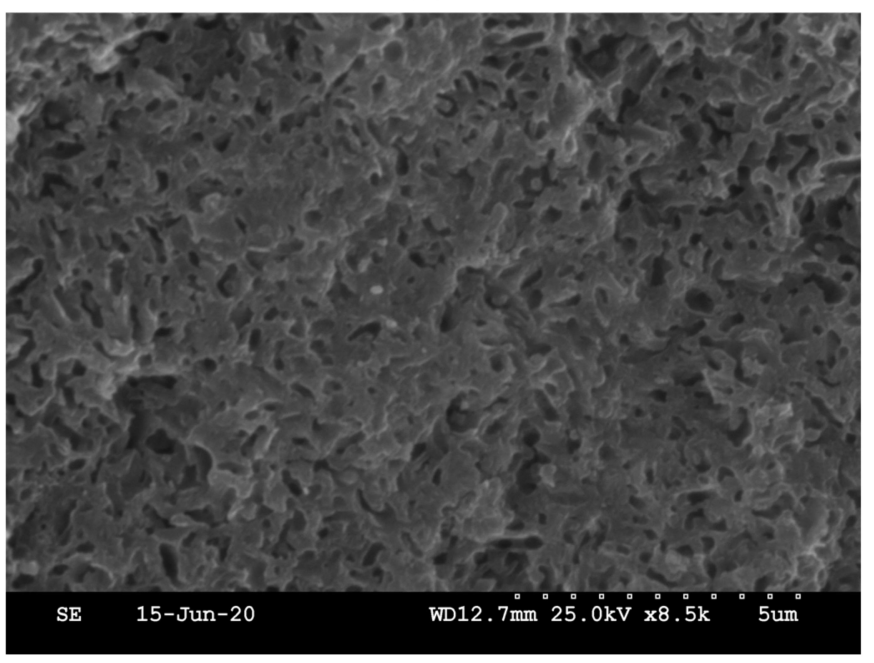

(d)

Figure 8. Fresh facture images on SEM of colloidal silica pastes with a $50{ }^{\circ} \mathrm{C}$ curing after 4.5 months of hydration: (a) and (c) M/S = 1.3, (b) $\mathrm{M} / \mathrm{S}=0.78$ and (d) $\mathrm{M} / \mathrm{S}=1$.

\subsection{Solid Composition}

X-ray diffractograms of three M-S-H pastes are presented in Figure 9. The humps of M-S-H (see Table 3 for positions) were observed on all diffractograms $[32,46,66]$. No brucite peaks were identifiable. The proportion of second broad reflection $(\sim 26[2 \Theta] \mathrm{CuK} \alpha)$ relative to the rest of the diffractogram increased along with the M/S ratio, as was the case 
for diffractograms of M-S-H powders of Bernard (dashed lines in Figure 9) [43]. The first broad reflection $(20[2 \Theta] \mathrm{CuK} \alpha)$ simultaneously decreased, indicating a rearrangement of the structure as the $\mathrm{M} / \mathrm{S}$ ratio increased. As proposed by Bernard, the first broad reflection would be linked to a structure similar to talc (a natural analogue of M-S-H) while the second broad reflection would be linked to serpentine. Thus, the X-ray diffractograms indicated a rearrangement of the structure with the increase in $\mathrm{M} / \mathrm{S}$, from a talc-like structure to serpentine, as Nied et al. observed in 2016 [32].

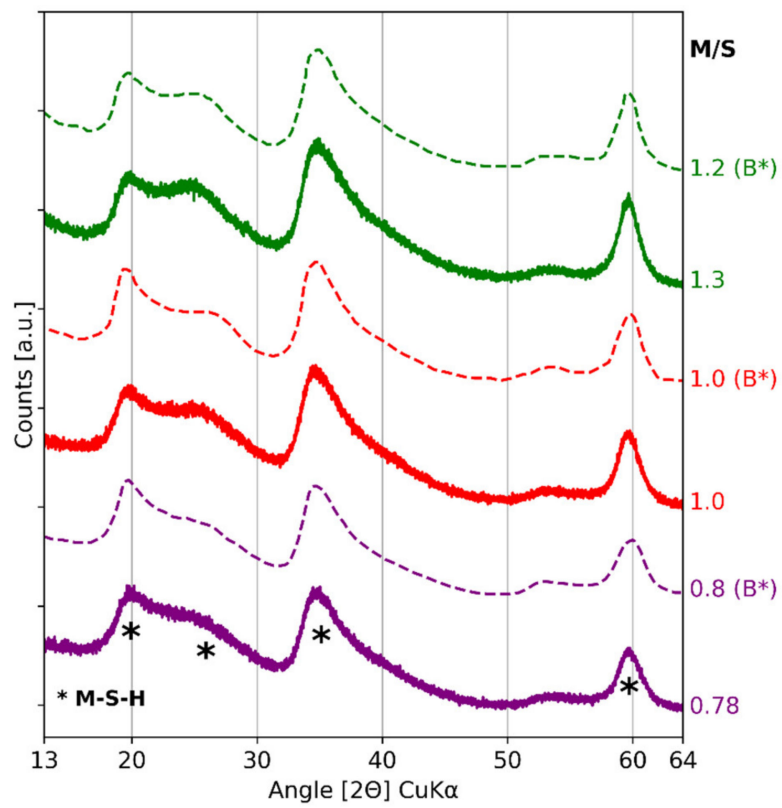

Figure 9. X-ray diffractograms of three M-S-H pastes with colloidal silica after 4.5 months of a $50{ }^{\circ} \mathrm{C}$ curing and three M-S-H powders synthetized by Bernard et al. [43] (dashed lines, noted B*). Manual mixing was used for pastes $\mathrm{M} / \mathrm{S}=0.78$ and $\mathrm{M} / \mathrm{S}=1.3$; mechanical mixing was used for $\mathrm{M} / \mathrm{S}=1$.

The TGA curves of M-S- $\mathrm{H}$ pastes and the derivative weight losses are shown in Figure 10. Brucite $\left(400-420{ }^{\circ} \mathrm{C}\right)$ was absent. The three water loss regions expected for M-S-H were observable. The first water $\left(30-280^{\circ} \mathrm{C}\right.$ ) loss region was linked to $\mathrm{H}_{2} \mathrm{O}$ (poorly bounded) loss in M-S-H.

The second and third water losses have been attributed to silanol and/or magnesium hydroxyl groups in M-S-H, but they may also comprise water present as a monolayer on the M-S-H surface $[32,43,52]$. Their attribution is controversial. Table 4 recaps the views and assumptions of various authors. The structure of M-S-H has been compared to that of many phyllosilicates (sepiolite, talc, etc.) [32,33,35,38,43]. Nied et al. [32] suggested that the weight loss between $280^{\circ} \mathrm{C}$ and $750{ }^{\circ} \mathrm{C}$ corresponds to hydroxyl groups with $\mathrm{Mg}^{2+}$, while the one between $750{ }^{\circ} \mathrm{C}$ and $840{ }^{\circ} \mathrm{C}$ would be linked to silanol groups on M-S-H. In the case of synthetic talc, Dumas et al. [67] attributed the weight loss $\left(150-450{ }^{\circ} \mathrm{C}\right)$ to silanol $(\mathrm{Si}-\mathrm{OH})$ and magnesium $(\mathrm{Mg}-\mathrm{OH})$ hydroxides on the sheet edges. The next loss $\left(450-750^{\circ} \mathrm{C}\right)$ would be linked to the dehydroxylation of small particles, whereas the high temperature loss $\left(750-850^{\circ} \mathrm{C}\right)$ would correspond to the dehydroxylation of bigger particles and the formation of enstatite and silica. For Bernard et al. [43], and according to the work of Zhuravlev [68] on amorphous silica, the weight loss around $390^{\circ} \mathrm{C}$ (observable IN Figure 10 on curves $\mathrm{M} / \mathrm{S}=0.78,0.8$ and 1 ) would match the dehydroxylation of silanol groups (on the surface) while the weight loss at $500{ }^{\circ} \mathrm{C}$ would be related to dehydroxylation of $\mathrm{Mg}-\mathrm{OH}$ in $\mathrm{M}-\mathrm{S}-\mathrm{H}$. Moreover, the removal of internal $\mathrm{OH}$ groups of silanols happened at around $900{ }^{\circ} \mathrm{C}$. 


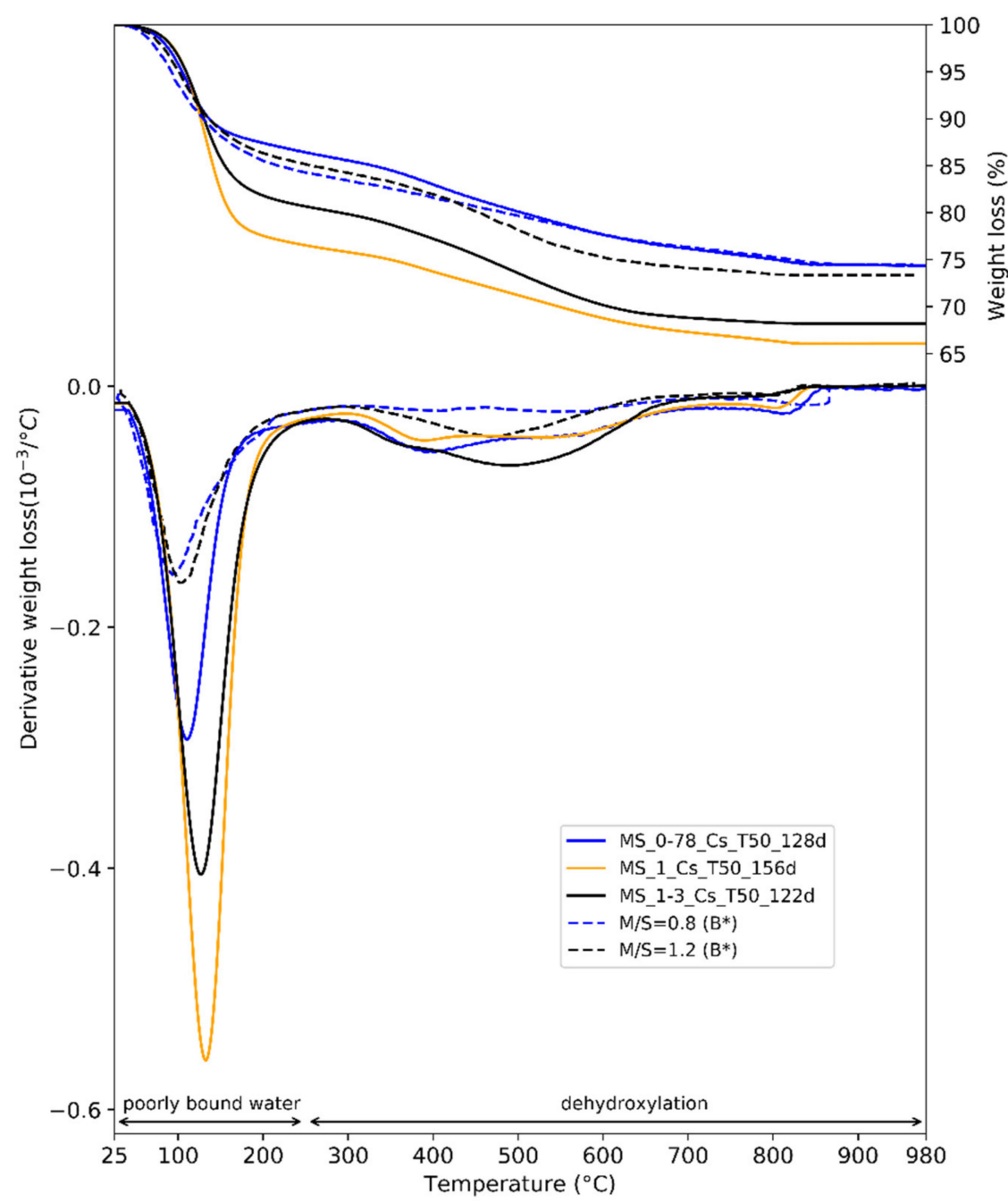

Figure 10. TGA results of three M-S-H pastes with colloidal silica after 4.5 months of a $50{ }^{\circ} \mathrm{C}$ curing and two M-S-H powders synthetized by Bernard et al. [43] (dashed lines, noted B*). Manual mixing was used for pastes $M / S=0.78$ and $M / S=1.3$; mechanical mixing was used for $M / S=1$.

Table 4. Different attributions of weight losses in TGA for M-S-H or correlated phases.

\begin{tabular}{|c|c|c|c|c|}
\hline Author & $\begin{array}{l}\text { Species } \\
\text { Concerned }\end{array}$ & \multicolumn{3}{|c|}{ Temperature and Phase Associated to Weight Losses } \\
\hline Lothenbach et al. [52] & M-S-H & \multicolumn{3}{|c|}{$\begin{array}{l}270-700^{\circ} \mathrm{C} \\
\text { hydroxyl groups in M-S-H }\end{array}$} \\
\hline Nied et al. [32] & M-S-H & \multicolumn{2}{|c|}{$\begin{array}{c}280-750{ }^{\circ} \mathrm{C} \\
\mathrm{Mg}-\mathrm{OH} \text { in } \mathrm{M}-\mathrm{S}-\mathrm{H}\end{array}$} & $\begin{array}{c}750-840{ }^{\circ} \mathrm{C} \\
\text { Si-OH in M-S-H }\end{array}$ \\
\hline Dumas et al. [67] & talc & $\begin{array}{c}150-450{ }^{\circ} \mathrm{C} \\
\mathrm{Mg}-\mathrm{OH} \text { and } \mathrm{Si}-\mathrm{OH}\end{array}$ & $\begin{array}{c}450-750{ }^{\circ} \mathrm{C} \\
\text { small particles }\end{array}$ & $\begin{array}{c}750-8500^{\circ} \mathrm{C} \\
\text { big particles }\end{array}$ \\
\hline Zhuralev [68] & $\begin{array}{l}\text { amorphous } \\
\text { silica }\end{array}$ & $\begin{array}{l}190-400{ }^{\circ} \mathrm{C} \\
\text { vicinal bridged } \mathrm{OH} \\
\text { groups of silanols }\end{array}$ & $\begin{array}{c}400-900^{\circ} \mathrm{C} \\
\text { geminal } \mathrm{OH} \\
\text { groups of silanols }\end{array}$ & $\begin{array}{c}900-1200{ }^{\circ} \mathrm{C} \\
\text { complete removal } \\
\text { of all OH groups }\end{array}$ \\
\hline Bernard et al. [43] & M-S-H & $\begin{array}{c}390^{\circ} \mathrm{C} \\
\text { surface } \mathrm{Si}-\mathrm{OH} \text { in } \\
\mathrm{M}-\mathrm{S}-\mathrm{H}\end{array}$ & $\begin{array}{c}500{ }^{\circ} \mathrm{C} \\
\mathrm{Mg}-\mathrm{OH} \text { in } \mathrm{M}-\mathrm{S}-\mathrm{H}\end{array}$ & $\begin{array}{c}900-1200{ }^{\circ} \mathrm{C} \\
\text { internal Si-OH in } \\
\text { M-S-H }\end{array}$ \\
\hline
\end{tabular}

The position shared by the authors quoted is the following: (i) the weight losses between $200{ }^{\circ} \mathrm{C}$ and $800{ }^{\circ} \mathrm{C}$ for M-S-H systems are linked to the dehydroxylation of a 
hydroxyl group in M-S-H, and (ii) the potential offsets of the losses are linked to the evolution of the structure of M-S-H. With regard to the type of hydroxyl groups associated with each temperature, the most recent and documented assumption (Bernard et al. [43]) was chosen.

The second water loss region between $280{ }^{\circ} \mathrm{C}$ and $750{ }^{\circ} \mathrm{C}$ differed with the M/S ratio (Figure 10). For $M / S=0.78$ and $M / S=1$, the second hump was located in the same place, while for $M / S=1.3$ the second hump was shifted to the right. The offset of the hump (400-500 ${ }^{\circ} \mathrm{C}$ ) resulting from the increase in M/S from $0.78-1$ to 1.3 also appeared on the TGA on M-S-H powders from Bernard et al. and Nied et al. [32,43]. The height of the last water loss region between $750{ }^{\circ} \mathrm{C}$ and $840{ }^{\circ} \mathrm{C}$ also evolved with the M/S. The amount of bound water increased along with the magnesium content. As the weight loss around $400{ }^{\circ} \mathrm{C}$ has been associated to surface $\mathrm{Si}-\mathrm{OH}$ and the weight loss around $500{ }^{\circ} \mathrm{C}$ to $\mathrm{Mg}-\mathrm{OH}$ in $\mathrm{M}-\mathrm{S}-\mathrm{H}$ [43], the offset of the hump would indicate the formation of more $\mathrm{Mg}-\mathrm{OH}$ groups with the increase in $\mathrm{M} / \mathrm{S}$. For $\mathrm{M} / \mathrm{S}=1.3$, the broader weight loss around $500{ }^{\circ} \mathrm{C}$ covered the weight loss around $400{ }^{\circ} \mathrm{C}$ of $\mathrm{M} / \mathrm{S}=0.78$ and $\mathrm{M} / \mathrm{S}=1$, indicating that the amount of surface $\mathrm{Si}-\mathrm{OH}$ groups remains stable. Conversely, the decrease in height of the weight loss peak around $800{ }^{\circ} \mathrm{C}$ as M/S increases would indicate a decrease in the internal Si-OH content of M-S-H. Thus, the internal structure of M-S-H would evolve with M/S.

The structure of M-S-H has been compared to that of many phyllosilicates (sepiolite, talc, etc.) and characterized as a sheet structure evolving with the M/S [32,33,35,38,43]. The silicate sheets would be linked by layers of octahedral-coordinated $\mathrm{Mg}^{2+}$ ions [32], with water present both as adsorbed water and in structure as $\mathrm{H}_{2} \mathrm{O}$ and hydroxyl groups [43]. As the X-ray diffractograms (Figure 9) illustrate, the interlayer distance decreases while $\mathrm{M} / \mathrm{S}$ in M-S-H increases [43], as is the case for C-S-H when the calcium to silicon (C/S) ratio increases [69]. According to the TGA results (Figure 10), this reduction of the interlayer distance would be associated with the formation of $\mathrm{Mg}-\mathrm{OH}$ in $\mathrm{M}-\mathrm{S}-\mathrm{H}$, with internal silanol groups being reduced. The evolution mechanism of the M-S-H structure with the variation of $\mathrm{M} / \mathrm{S}$ would then be similar to that of the C-S-H with the variation of C/S. A possible parallel could be inferred between the $\mathrm{Ca}-\mathrm{OH}$ that forms between the chains of $\mathrm{Ca}-\mathrm{Si}$ and the $\mathrm{Mg}-\mathrm{OH}$ that would form between the layers of $\mathrm{Mg}-\mathrm{Si}$ as $\mathrm{C} / \mathrm{S}$ or $\mathrm{M} / \mathrm{S}$ increase.

The two analyses allowed to describe the pastes as composed only of M-S-H. The evolution of the structure with M/S appeared in the XRD and TGA. Talc-like characteristics were observed at low $\mathrm{M} / \mathrm{S}$, while serpentine-like reflections were associated with high $\mathrm{M} / \mathrm{S}$. Moreover, we detected an increase in the $\mathrm{Mg}-\mathrm{OH}$ content of $\mathrm{M}-\mathrm{S}-\mathrm{H}$ as $\mathrm{M} / \mathrm{S}$ increased.

\subsection{Microstructure and Porosity}

Several techniques were used to characterize the microstructure and porosity of M-S$\mathrm{H}$ pastes. Figure 1 illustrates the panel of porosity characterizations associated with the dimensional range of solids and pores in an M-S-H paste. In this section, we propose the characterization of the porous structure starting from the smallest (physisorption) to the largest scale (water saturation). Since the mixing protocol and the $\mathrm{w} / \mathrm{b}$ could influence the structure and porosity of a paste, the tests were carried out on both pastes with manual (noted $\mathrm{M}, \mathrm{w} / \mathrm{b} \sim 1.45$ ) and mechanical (noted $\mathrm{E}, \mathrm{w} / \mathrm{b} \sim 1.1$ ) mixing. The results presented correspond to pastes MS_0-78_CS_T50_M/E, MS_1_CS_T50_E, and MS_1-3_CS_T50_M/E.

Figure 11 shows the $\mathrm{N}_{2}$ adsorption-desorption isotherms of $\mathrm{M}-\mathrm{S}-\mathrm{H}$ samples made with $\mathrm{M} / \mathrm{S}=0.78, \mathrm{M} / \mathrm{S}=1.0$ and $\mathrm{M} / \mathrm{S}=1.3$, mixed manually (Figure $11 \mathrm{~b}$ ) or mechanically (Figure 11a). The mixing protocol and the $\mathrm{w} / \mathrm{b}$ seemed to influence the form of the isotherm at relative pressures $>0.7$ (for both the adsorption and desorption curves). The mechanical mixing-associated to a lower $\mathrm{w} / \mathrm{b}$-resulted in a smoother desorption for very high relative pressures and a lower adsorbed quantity. In the range $\mathrm{p} / \mathrm{p}^{0}=\{0 ; 0.7\}$ the mixing process and $\mathrm{w} / \mathrm{b}$ had no influence, probably due to the creation of "bigger" pores with manual mixing (where the $\mathrm{w} / \mathrm{b}$ was higher). The internal structure of M-S-H remained the same since low pressures were not affected. 

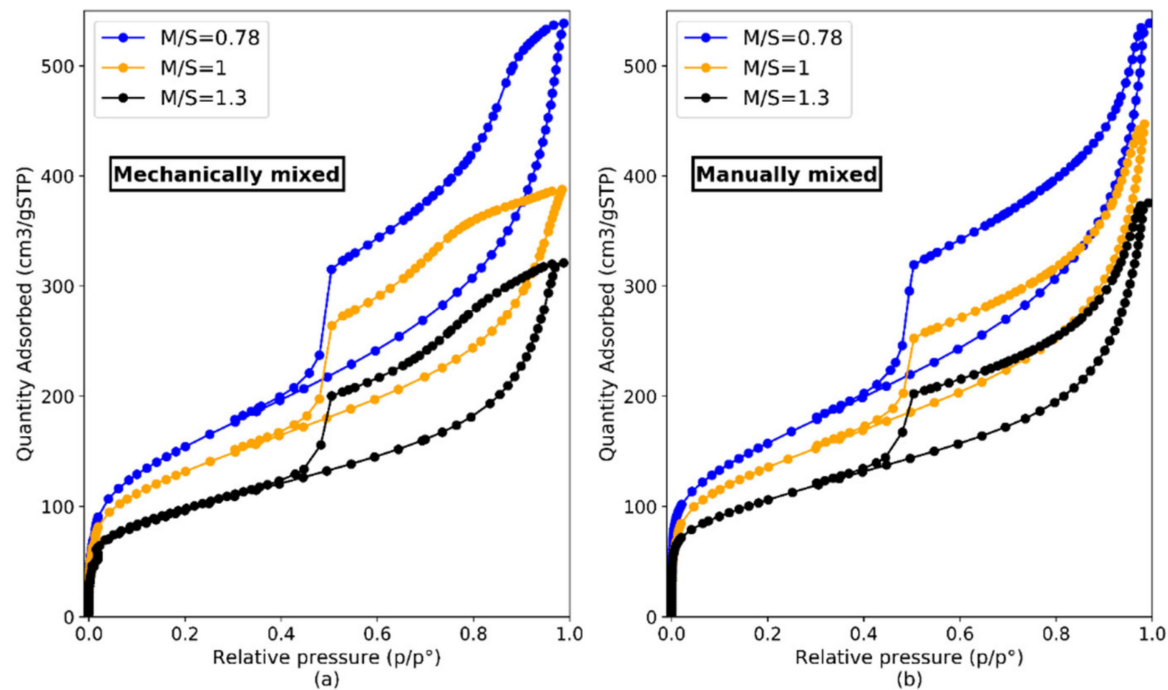

Figure 11. $\mathrm{N}_{2}$ adsorption-desorption isotherms of $\mathrm{M}-\mathrm{S}-\mathrm{H}$ samples with $\mathrm{M} / \mathrm{S}=0.78, \mathrm{M} / \mathrm{S}=1.0$ and $\mathrm{M} / \mathrm{S}=1.3$, mixed mechanically (a) or manually (b).

Figure 12 illustrates the different types of isotherms and hysteresis loops following the IUPAC classification [70]. The isotherms presented a hysteresis loop characteristic of a Type IV isotherm according to this classification. The adsorption part of the Type IV isotherm could be attributed to a monolayer-multilayer adsorption. The initial vertical slope at low $\mathrm{p} / \mathrm{p}^{0}$ was characteristic of the presence of microporosity (equivalent diameter between $0.4 \mathrm{~nm}$ and $2 \mathrm{~nm}$ ).

Types of physisorption isotherms

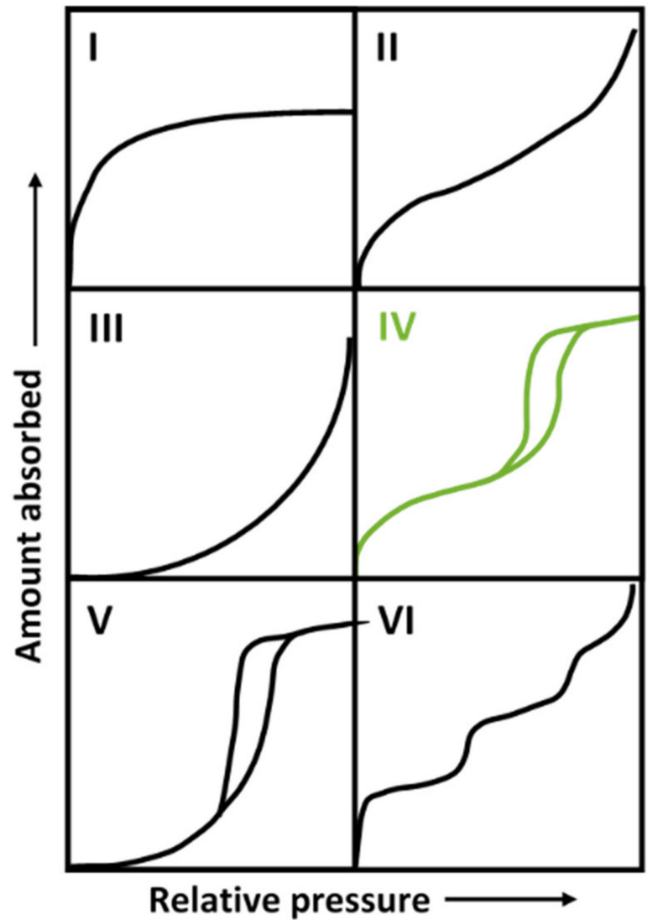

(a)

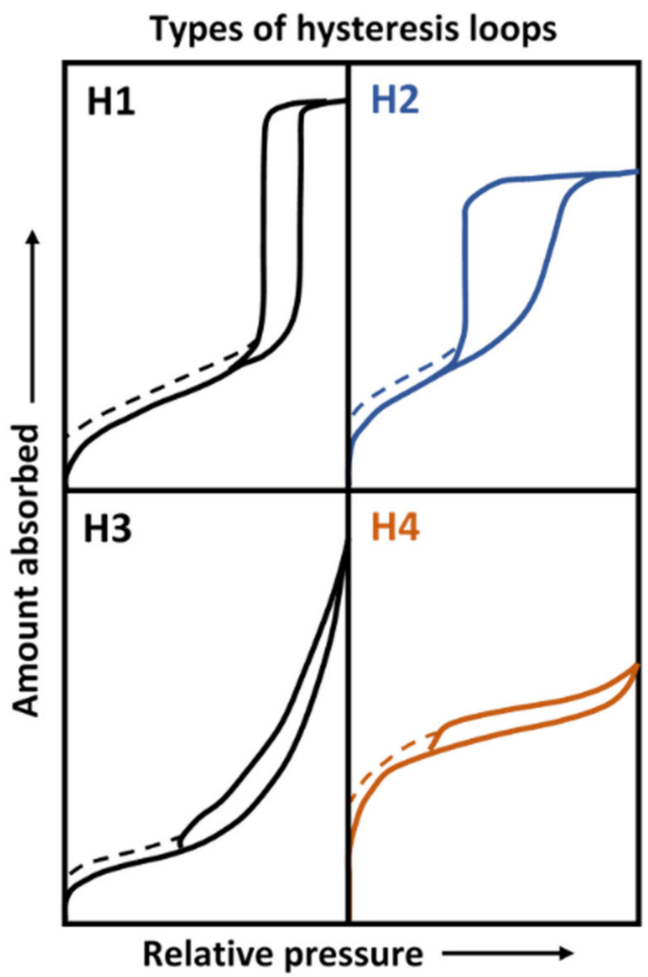

(b)

Figure 12. Types of physisorption isotherms (a) and hysteresis loops (b) (after Sing [70]).

Hysteresis has been associated with capillary condensation taking place in mesopores (2-50 $\mathrm{nm}$ in diameter) [43]. M-S-H pastes made by mechanical mixing (lowest $\mathrm{w} / \mathrm{b}$ ), exhibited hysteresis comparable to $\mathrm{H} 4$ types with a small portion of the curve (on desorption 
at high $\mathrm{p} / \mathrm{p}^{0}$ ) which would correspond to $\mathrm{H} 2$ type. The Type $\mathrm{H} 4$ loop is associated with narrow slit-like pores while the Type $\mathrm{H} 2$ is harder to interpret and is often associated with pore size and a not well-defined shape [70]. The form of the high pressure hysteresis for mechanically mixed pastes could therefore relate to the presence of specific bottleneck-shaped pores [71]. Overall, the structure we observed corresponded to plate-like materials with mesopores. The shape of the isotherms-especially of manually mixed pastes (highest $\mathrm{w} / \mathrm{b}$ ) - resembled that of synthetic saponite-like materials prepared by traditional hydrothermal crystallization at $513 \mathrm{~K}$ with $\mathrm{H}_{2} \mathrm{O} / \mathrm{SiO}_{2}=50$ by Bisio et al. [72]. The form of the hysteresis was also similar to that of the M-S-H powders synthesized by Bernard [43] under hydrothermal treatment $\left(180^{\circ} \mathrm{C}\right.$ for 4 days $)$.

According to Figure 11, the M/S ratio of M-S-H pastes appeared to influence the amount of $\mathrm{N}_{2}$ adsorbed: the lower the $\mathrm{M} / \mathrm{S}$, the higher the total $\mathrm{N}_{2}$ adsorbed.

The specific surface areas calculated with BET (SSA $\left.{ }_{\mathrm{BET}}\right)$ on M-S-H pastes hydrated from 2 (mechanically mixed) to 7.5 months (manually mixed; $M / S=1$ is an exception, as it was hydrated for 2.5 months) are displayed in Table 5. Figure 13 illustrates the evolution of the specific surface as a function of the M/S ratio and the mixing protocol. Bernard's data obtained on synthetic powders [43] are plotted in blue and green.

Table 5. Average specific surfaces and volume calculated for M-S-H pastes (colloidal silica and thermal cure at $50^{\circ} \mathrm{C}$ ) using BET and t-plot methods from nitrogen isotherms.

\begin{tabular}{ccccccc}
\hline & \multicolumn{3}{c}{ Mechanically Mixed } & \multicolumn{3}{c}{ Manually Mixed } \\
\hline $\mathrm{M} / \mathrm{S}$ & 0.78 & 1 & 1.3 & 0.78 & 1 & 1.3 \\
$\mathrm{w} / \mathrm{b}$ & 1.1 & 1 & 1.1 & 1.45 & 1.45 & 1.45 \\
Age (days) & 70 & 50 & 70 & 230 & 70 & 230 \\
(m $\left.^{2} / \mathrm{g}\right)$ & 556.7 & 475.2 & 345.3 & 562.9 & 488.2 & 381.6 \\
Average specific surface area BET & 1.2 & 0.8 & 1.1 & 0.8 & 1.1 & 0.6 \\
Medium uncertainty & 11.7 & 3.7 & 6.6 & 8.7 & 8.1 & 3.0 \\
Standard deviation & 416.6 & 296.8 & 230.6 & 394.9 & 314.6 & 249.8 \\
External average specific surface & & & & & & \\
area (t-plot) $\left(\mathrm{m}^{2} / \mathrm{g}\right)$ & 6.5 & 1.8 & 7.4 & 26.3 & 5.4 & 9.5 \\
Standard deviation & 230.0 & 193.5 & 142.3 & 235.0 & 198.3 & 158.3 \\
$\mathrm{~V}_{\text {tot }}\left(\mathrm{cm}^{3} / \mathrm{g}\right)$ & 5.0 & 2.1 & 2.5 & 5.0 & 2.9 & 2.9 \\
Standard deviation & 0.355 & 0.299 & 0.220 & 0.363 & 0.307 & 0.245 \\
Pore volume $\left(\mathrm{cm}^{3} / \mathrm{g}\right)$ & & & & & &
\end{tabular}

High SSA $_{\mathrm{BET}}$ were close to large surface areas reported by Bernard [43] for powders with a similar curing ( 1 year at $\left.50{ }^{\circ} \mathrm{C}\right)$. As expressed by Bernard, specific surfaces were much lower for samples cured for 3.3 years at $20^{\circ} \mathrm{C}$ due to a longer hydration time. Over time, the porous network could evolve. Initially, magnesium phases are formed upon contact between water and magnesium oxide and/or silica. As is the case with inner C-S-H [73], denser M-S-H could gradually be formed in the inner layer of reacted silica fume clusters, which would result in finer porosity, lower specific surface areas and lower pore volumes. In the case of M-S-H pastes with colloidal silica, no silica clusters were formed, reducing the possibility of a more dense M-S-H formation.

Contrary to Bernard's hypothesis, according to which M-S-H forms in non-diluted systems or might exhibit a smaller SSA in field experiments, the experiments presented in this paper proved that M-S-H pastes showed similar specific surfaces to powders, both cured at $50{ }^{\circ} \mathrm{C}$. The specific surface seemed independent of the mixing protocol for low $\mathrm{M} / \mathrm{S}$ ratios $(0.78$ and 1$)$. The $\mathrm{SSA}_{\mathrm{BET}}$ decreased with the $\mathrm{M} / \mathrm{S}$ ratio in $\mathrm{M}-\mathrm{S}-\mathrm{H}$ with a slightly different slope from that of Bernard's data. At high $M / S(M / S=1$ and $M / S=1.3)$, a gap arose between the data of Bernard, the data for manual mixing $(\mathrm{w} / \mathrm{b}=1.45)$ and the data for mechanical mixing $(\mathrm{w} / \mathrm{b}=1.1)$. The measurement uncertainty and the standard deviation (obtained by repeating the test) are too low to explain the difference in value between the protocols for these $\mathrm{M} / \mathrm{S}$ values. High $\mathrm{M} / \mathrm{S}$ ratios seem to be more affected by curing time and type of mixing. As for the effect of the mixing protocol at high $\mathrm{M} / \mathrm{S}$ - highlighted in 
Section 3.2.- - the high content of $\mathrm{MgO}$ compared to $\mathrm{SiO}_{2}$ implies a slower consumption of brucite. This could explain a different low-scale organization of the material between the pastes, following the initial brucite content (brucite is a crystallized phase, as opposed to $\mathrm{M}-\mathrm{S}-\mathrm{H})$. The consumption of brucite to form M-S-H in a hardening shape could produce a different porous network.

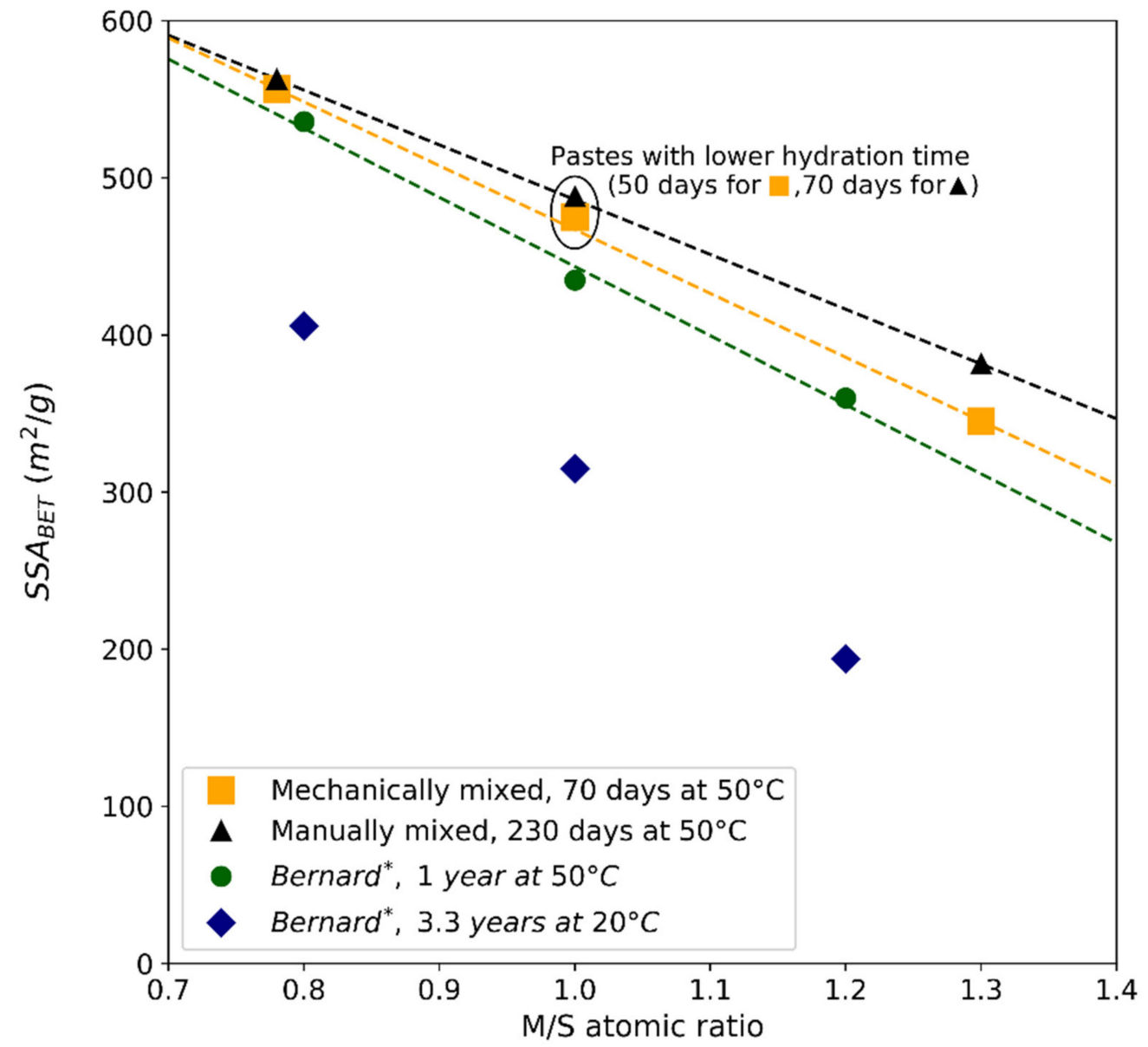

Figure 13. Specific surface area $\left(\mathrm{SSA}_{\mathrm{BET}}\right)$ found in $\mathrm{M}-\mathrm{S}-\mathrm{H}$ pastes as a function of the M/S atomic ratio and of the mixing protocol. The dotted lines are the trend lines from the mechanically mixed (orange), manually mixed (black) and * Bernard et al. [43] measurements (green: M-S-H powders equilibrated for 1 year at $50{ }^{\circ} \mathrm{C}$; blue: M-S-H powders equilibrated for 3.3 years at $20^{\circ} \mathrm{C}$ ).

Pore volumes and $S_{S A}$ ext are plotted in Figure 14. As was the case with $\mathrm{SSA}_{\mathrm{BET}}$, the values measured were higher than those of Bernard on powders equilibrated for 3.3 years at $20^{\circ} \mathrm{C}$ [43]. No value was presented by Bernard on samples equilibrated for 1 year at $50{ }^{\circ} \mathrm{C}$. $\mathrm{SSA}_{\text {ext }}$ and pore volumes were notably high for all our samples, implying a high content of micro- and mesopores. A clear trend was visible with the evolution of the M/S ratio. An increase in $\mathrm{M} / \mathrm{S}$ implied a decrease in external surface area and pore volume. The porosity of samples with high $\mathrm{M} / \mathrm{S}$ ratios $(\mathrm{M} / \mathrm{S}=1.3)$ seemed to contain less micro- and mesopores than the porosity of samples with low $M / S$ ratios $(M / S=0.78)$.

The pore size distribution between 2.5 and $8 \mathrm{~nm}$-according to the BJH method-is shown in Figure 15. All samples showed a peak around $4 \mathrm{~nm}$. The incremental pore volume $\left(\mathrm{cm}^{3} / \mathrm{g}\right)$ increased as the M/S atomic ratio decreased, confirming that the M-S-H pastes with high M/S contained less micro- and mesopores than the pastes with lower M/S. The common location of the peak and the similar appearance of the curves indicated that the mixing protocol and the $\mathrm{w} / \mathrm{b}$ did not influence this range of pores. 


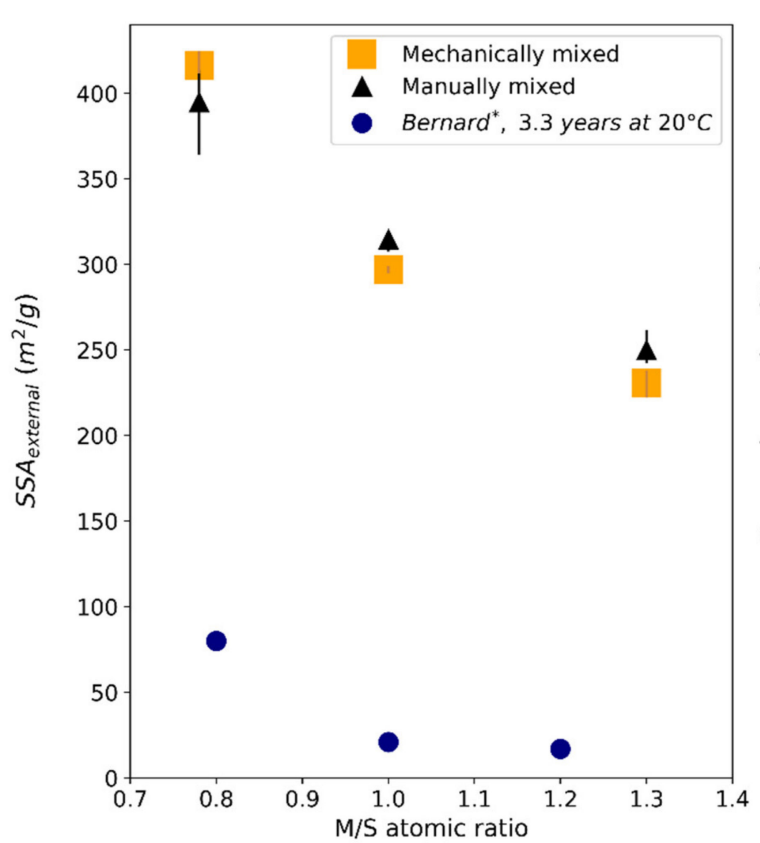

(a)

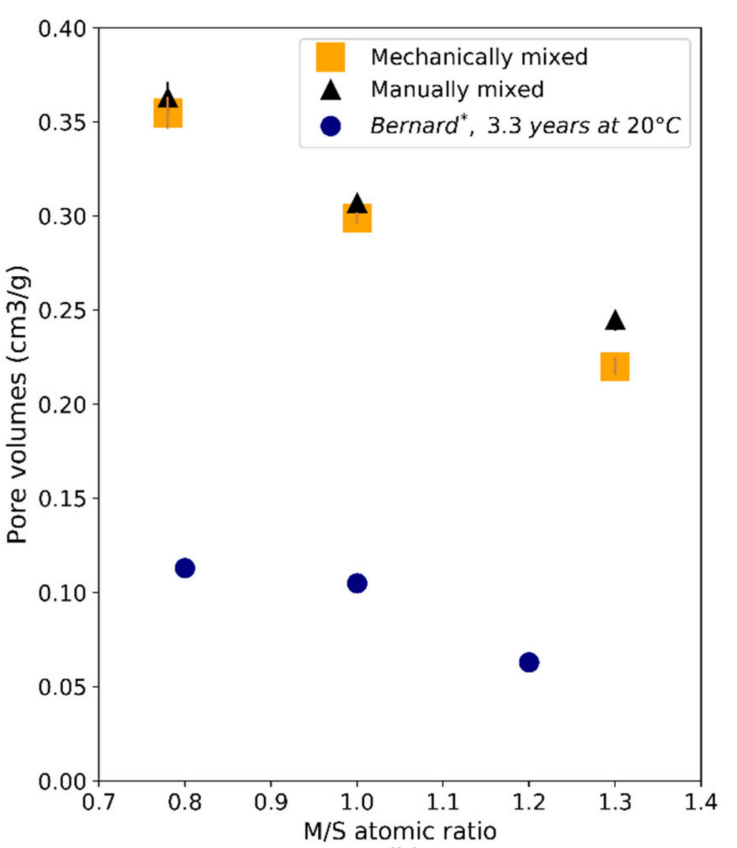

(b)

Figure 14. $\mathrm{SSA}_{\mathrm{ext}}(\mathbf{a})$ and pore volumes (b) obtained by t-plot in M-S-H pastes as a function of the $\mathrm{M} / \mathrm{S}$ atomic ratio and of the mixing protocol. * Bernard et al. measurements (in blue) correspond to M-S-H powders equilibrated for 3.3 years at $20^{\circ} \mathrm{C}$.

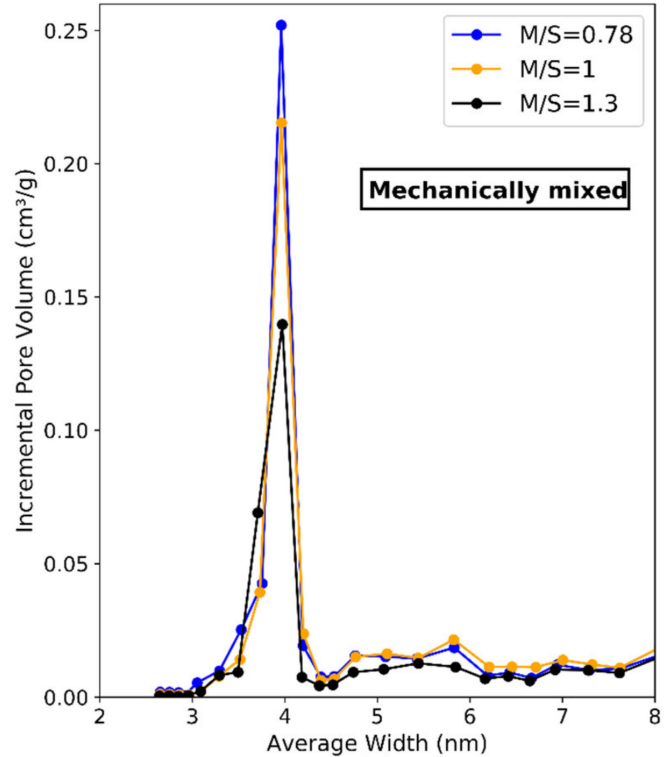

(a)

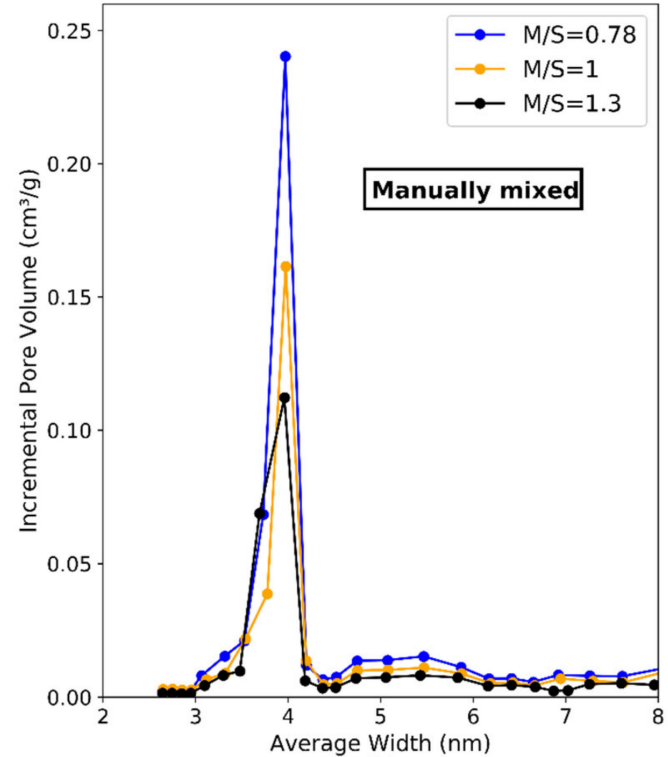

(b)

Figure 15. Pore size distribution by $\mathrm{N}_{2}$ physisorption of $\mathrm{M}-\mathrm{S}-\mathrm{H}$ samples with $\mathrm{M} / \mathrm{S}=0.78, \mathrm{M} / \mathrm{S}=1.0$ and $\mathrm{M} / \mathrm{S}=1.3$, mixed mechanically $(\mathbf{a})$ or manually $(\mathbf{b})$.

In order to characterize the pore size distribution at the higher scale, MIP was used. The pore size distribution between 8 and $4 \times 10^{5} \mathrm{~nm}$ is shown in Figure 16 . The pastes manually mixed showed a family of small pores between 8 and $10 \mathrm{~nm}$ with a high peak centered at $26 \mathrm{~nm}$, while the mechanically mixed pastes only exhibited a family of pores with a mean value centered at $9 \mathrm{~nm}$. A manual mixing associated to a high $\mathrm{w} / \mathrm{b}(1.45)$ therefore influenced the size and distribution of the mesopores by creating supplementary capillary pores (26 nm in diameter). The porosity values (Table 6) obtained with MIP will be discussed in the following paragraphs. 


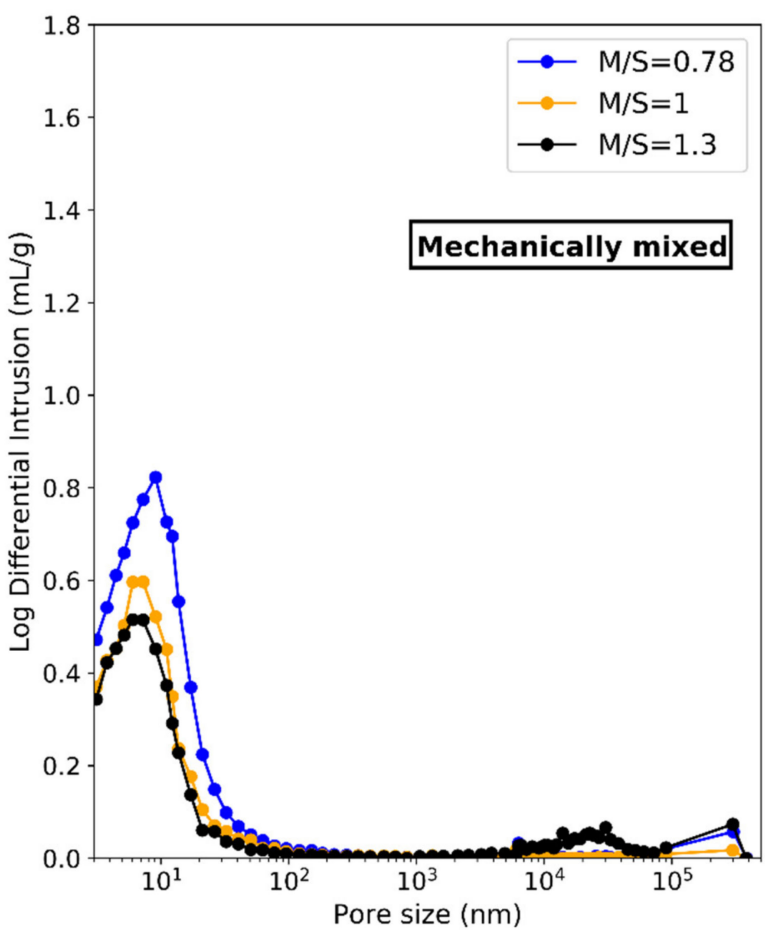

(a)

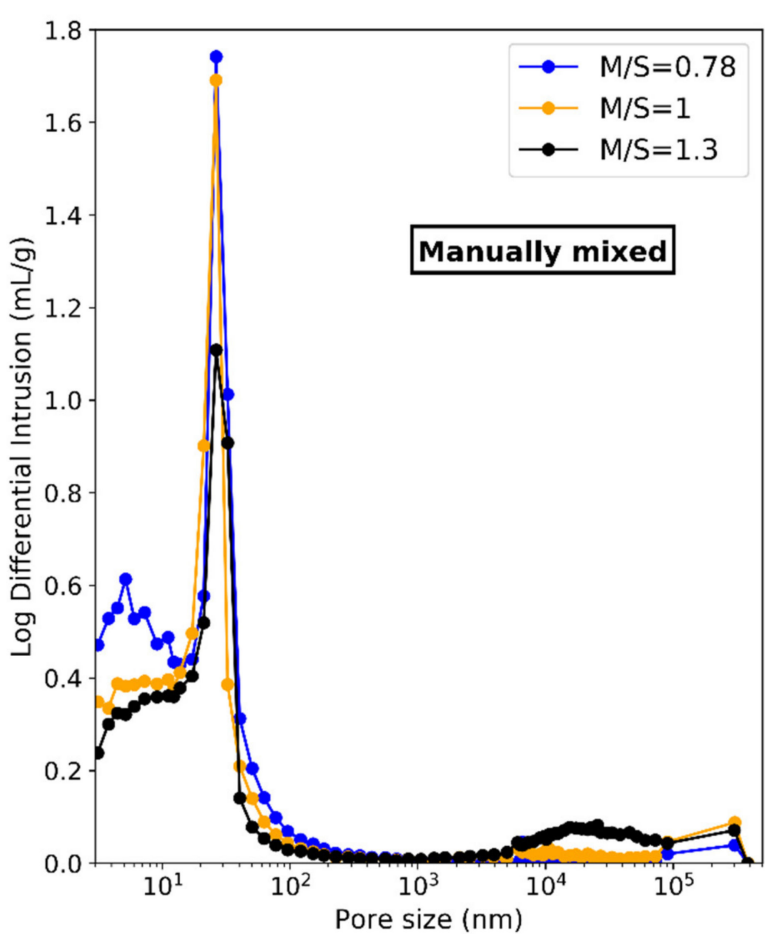

(b)

Figure 16. Pore size distribution by mercury intrusion porosimetry (MIP) of M-S-H samples with $\mathrm{M} / \mathrm{S}=0.78,1.0$ and 1.3, mixed mechanically (a) or manually (b).

Table 6. Porosity of the M-S-H pastes according to MIP, kerdane and helium pycnometry, autoradiography, and water porosity.

\begin{tabular}{|c|c|c|c|c|c|c|c|}
\hline & \multirow[b]{2}{*}{$\mathrm{M} / \mathrm{S}$} & \multicolumn{3}{|c|}{ Mechanically Mixed } & \multicolumn{3}{|c|}{ Manually Mixed } \\
\hline & & 0.78 & 1 & 1.3 & 0.78 & 1 & 1.3 \\
\hline & $\mathrm{w} / \mathrm{b}$ & 1.1 & 1 & 1.1 & 1.45 & 1.45 & 1.45 \\
\hline & Age (days) & 120 & 430 & 120 & 430 & 120 & 430 \\
\hline MIP & Porosity (\%) & 46.54 & 39.71 & 39.17 & 46.83 & 46.38 & - \\
\hline \multirow{3}{*}{$\begin{array}{l}\text { Kerdane and } \\
\text { helium } \\
\text { pycnometry }\end{array}$} & Bulk density $\left(\mathrm{g} / \mathrm{cm}^{3}\right)$ & 0.83 & 0.88 & 0.84 & 0.75 & 0.67 & 0.71 \\
\hline & True density $\left(\mathrm{g} / \mathrm{cm}^{3}\right)$ & 2.23 & 2.30 & 2.22 & 2.30 & 2.34 & 2.31 \\
\hline & Porosity $(\%)$ & 62.86 & 61.78 & 61.89 & 67.60 & 71.39 & 69.17 \\
\hline $\begin{array}{l}\text { Auto- } \\
\text { radiography }\end{array}$ & $\begin{array}{c}\text { Porosity }(\%) \text {-Aged of } \\
180 \text { days }\end{array}$ & - & - & - & 75.2 & - & 66.4 \\
\hline Water Porosity & Porosity (\%) & 77.62 & 70.08 & 71.03 & 86.14 & 78.79 & 74.69 \\
\hline
\end{tabular}

Autoradiography was useful for establishing a link between the pore distribution and the overall porosity of the material, since it provides a 2D image of void percentage on samples and a histogram of the void percentage distribution. Autoradiography analyses were carried on three samples (one for $M / S=0.78$ and two for $M / S=1.3$ ). Figure $17 \mathrm{a}-\mathrm{c}$ show the autoradiography maps. A cracking phenomenon-similar to shrinkage-appeared in the samples (Figure 17b,c) as soon as water was removed from them by drying, vacuum, etc. This experimental perturbation did not prevent us from analyzing the porosity of the samples through the extraction of cracks and bubbles by deconvolution of the porosity histograms. The histograms associated with the maps (Figure 17d-f) show the distribution of the void ratio (porous areas and cracks). In the histograms-where all kinds of features were taken into account — the highest values approximately reach $100 \%$. For $\mathrm{M} / \mathrm{S}=1.3$, three Gaussian distributions were used to reproduce the histogram. For $M / S=0.78$, only one Gaussian distribution was necessary. The characteristics of the Gaussian distributions 
are displayed in the histogram (Figure $17 \mathrm{~d}-\mathrm{f}$ ). For $\mathrm{M} / \mathrm{S}=1.3$, the first Gaussian distribution with $\mu=58 \%$ (sample 1 ) or $\mu=56.4 \%$ represented more than $80 \%$ of the histogram. The two other Gaussian distributions-with $\mu=72 \%$ and $\mu=89 \%$ (sample 1 ) or $\mu=68.9 \%$ and $\mu=85 \%$-would correspond to bubbles and cracks. The removal of cracks corresponded to considering only the first Gaussian for each histogram. The average value of the porosity obtained by further treatment would then be $57.2 \%$ for $\mathrm{M} / \mathrm{S}=1.3$ and $67.5 \%$ for $\mathrm{M} / \mathrm{S}=0.78$.

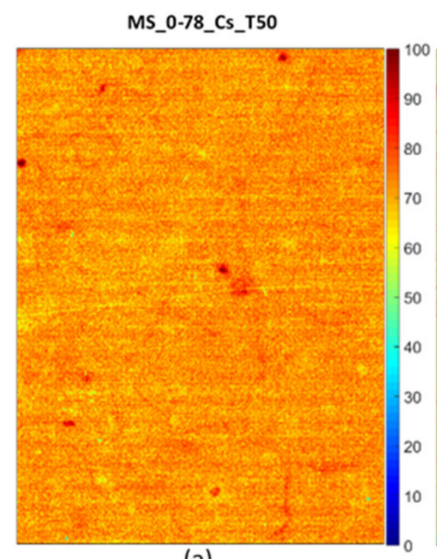

(a)

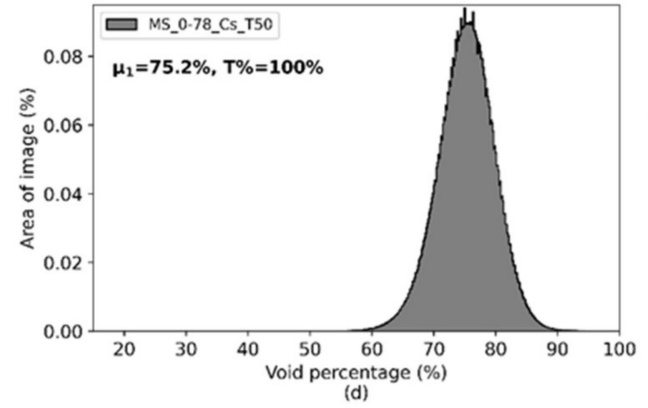

MS_1-3_CS_TSO

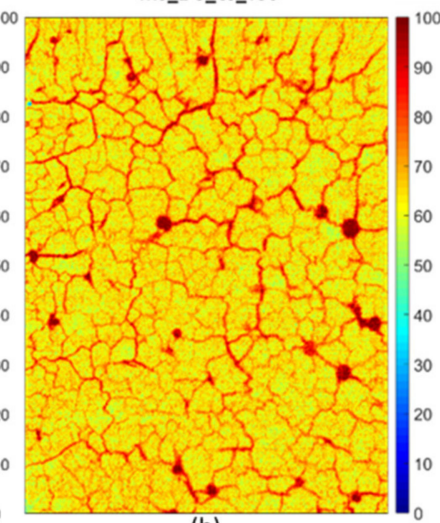

(b)

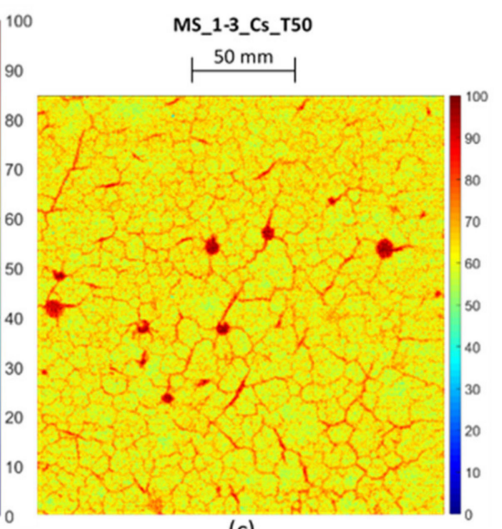

(c)

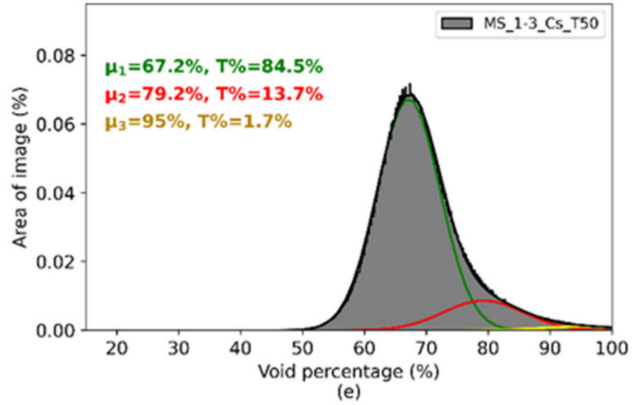

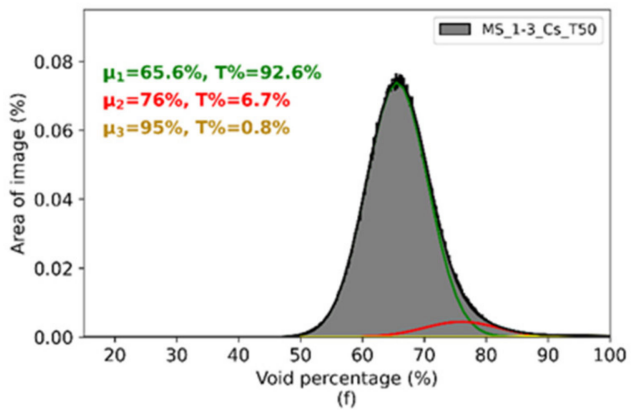

Figure 17. Autoradiography maps of M-S-H manually mixed pastes (a) $M / S=0.78 ;(\mathbf{b}, \mathbf{c}) \mathrm{M} / \mathrm{S}=1.3$ and associated porosity histograms and deconvolution-(d) for $(\mathbf{a}, \mathbf{e})$ for $(\mathbf{b}, \mathbf{f})$ for $(\mathbf{c}) . \mu$ is the mean of the phase and $\mathrm{T} \%$ corresponds to the percentage of the phase into the total histogram.

The M/S-dependent effect on cracking was observed in the autoradiography maps. As explained in Section 4.3 and observed in Figure 17, the sample with $M / S=1.3$ showed numerous bubbles and cracks. The sample with $\mathrm{M} / \mathrm{S}=1$ cracked during impregnation while the samples with $\mathrm{M} / \mathrm{S}=0.78$ did not show large cracks. According to Figure 15, the samples in question did not exhibit any difference in low-scale pore distribution, except for the amount of $\mathrm{N}_{2}$ adsorbed. Thus, the difference in the cracking pattern was not due to the finer distribution of the pores. While the pastes with the lowest $M / S(M / S=0.78)$ were the most porous, they underwent the least cracking. Preferential and faster cracking appearing for high M/S could therefore be linked to lower mechanical properties of the material.

Autoradiography and MIP provided a first idea of the total open porosity of the material. Other measurements were carried out in order to obtain a clearer picture of the porosity of the pastes (Table 6). The lowest porosity value was obtained with MIP, followed 
by the values acquired with helium pycnometry and kerdane, autoradiography and water porosity. These observations can be explained by the range and type of pores considered depending on the test.

MIP explored only the connected porosity; while pores $>8 \mathrm{~nm}$ were taken into account, large defects (air bubbles and very open cracks) were ignored. The porosity values obtained by helium pycnometry correspond to the open porosity, including cracks and bubbles. Autoradiography measured the connected porosities, with air bubbles and cracks being removed during post-processing (smallest visible pores $=10 \mu \mathrm{m}$ ). Water porosity took into account the connected porosity, bubbles and cracks. The latter is therefore the largest measured value. Moreover, the $105^{\circ} \mathrm{C}$ drying protocol used for water porosity may consume certain hydrates, resulting in a potential small overestimation of the actual porosity. As each method had its limitations, it was interesting to combine them all to characterize the material.

A general trend could still be observed. Manually mixed pastes had a slightly higher porosity $(10 \%$ more) than mechanically mixed ones (these results were consistent with the higher $\mathrm{w} / \mathrm{b}$ ratio used for manual mixing). Overall, the porosity of these pastes was high. The influence of the $\mathrm{M} / \mathrm{S}$ ratio on the overall porosity was difficult to assess because the pastes were very porous (due to the high $\mathrm{w} / \mathrm{b}$ ratio imposed). C-S-H pastes cast with a similar protocol (colloidal silica) also have a high porosity, close to $60 \%$ according to Kangni-Foli [74]. The effect of mixing and $w / b$ disappeared only on a smaller scale. According to Bernard [75], the molar volume of M-S-H increases with increasing M/S. It is expected that the higher the solid molar volume, the lower the pore volume [76]. This observation can be found in our study through $\mathrm{N}_{2}$ physisorption and MIP. The more the $\mathrm{M} / \mathrm{S}$ increases, the more the absorbed amounts of $\mathrm{N}_{2}$ and $\mathrm{Hg}$ and the specific surface area decrease, thus indicating a higher mesoporosity. On a larger scale, the porosities measured by the different techniques show this same trend. The pastes were mainly mesoporous, with a small amount of micropores and some defects appearing on a larger scale (bubbles due to mixing and cracks due to pre-treatments).

The microstructure of M-S-H pastes was characterized in this study. On a smaller scale, at the level of silica sheets (Figure 1), physisorption analyses described the material as a highly porous phase with plate-like micropores and mesopores. The increase in M/S implied a decrease in the quantity of $\mathrm{N}_{2}$ adsorbed, as well as a reduction of the specific surface $\left(\mathrm{SSA}_{\mathrm{BET}}\right)$, the $\mathrm{SSA}_{\mathrm{ext}}$ and the micro- and mesopore volume. At the level of capillary pores to clusters of globules of M-S-H (Figure 1), MIP was useful for distinguishing the effect of the mixing protocol. Mechanically mixed pastes exhibited a mesopore family around $10 \mathrm{~nm}$, while manual mixing also created a high amount of mesopores around $30 \mathrm{~nm}$. The mechanical mixing — which lasted longer and used a higher speed and strength-helped reduce the $w / b$, leading to a denser paste with less porosity. On a larger scale, porosity measurement protocols provided information about open porosity. On autoradiography maps, we observed the formation of cracks as soon as the water was removed from the samples. This mechanism highlighted the mechanical strength and sensibility of M-S-H in a relatively humid environment. The removal of cracks and bubbles from histograms of porosity showed the high open porosity of the pastes (approximately $60 \%$ for manually mixed pastes). This high value was supported by other characterization methods, although the porosity measurements were influenced by pre- or post-treatment of the samples. Drying at $105^{\circ} \mathrm{C}$ after water saturation and bulk density measurements could lead to the calcination of hydrates, resulting in an overestimated porosity. Overall, the open porosity of M-S-H pastes could be considered to be $70 \%$ for manually mixed pastes and $62 \%$ for mechanically mixed pastes, with this percentage increasing as the M/S ratio decreases.

\section{Conclusions}

This paper focused on the chemical and microstructural properties of cohesive M$\mathrm{S}-\mathrm{H}$ pastes. Four protocols to obtain cohesive and homogenous M-S-H pastes-without brucite or other species-were tested in this study. The increase in curing temperature 
$\left(20-50{ }^{\circ} \mathrm{C}\right.$ ) accelerated the consumption of brucite and favored the formation of M-S-H, with colloidal silica enabling a better distribution of particles than silica fume. The higher the M/S ratio, the longer the brucite was present. The protocol of choice for M-S-H manufacturing therefore involves colloidal silica and $\mathrm{MgO}$ with $\mathrm{w} / \mathrm{b}=1$ and mechanical mixing (140-285 rd/min rotation for $10 \mathrm{~min})$, followed by a thermal cure at $50{ }^{\circ} \mathrm{C}$ for 50 days (minimum recommended).

X-ray diffraction and thermogravimetric analyses indicated a rearrangement of the structure-from talc-like structure to serpentine-as M/S increased, linked to a decrease in the interlayer distance and an increase in the $\mathrm{Mg}-\mathrm{OH}$ content in $\mathrm{M}-\mathrm{S}-\mathrm{H}$. The evolution of the M-S-H structure would be similar to that of the C-S-H. A parallel could be drawn between the $\mathrm{Ca}-\mathrm{OH}$ that forms between the chains of $\mathrm{Ca}-\mathrm{Si}$ and the $\mathrm{Mg}-\mathrm{OH}$ that would form between the layers of $\mathrm{Mg}-\mathrm{Si}$ as $\mathrm{C} / \mathrm{S}$ or M/S increase.

The porosity of M-S-H pastes was studied from the level of entrained air bubbles and voids to the level of silica sheets. On a large scale, the combination of different characterization methods made it possible to quantify the total, open porosities of the pastes. Mechanical mixing reduced the open porosity from $70 \%$ (manual mixing) to $62 \%$. This value changed along with the M/S ratio in that the higher the ratio, the lower the porosity. On a smaller scale-from the capillary pores to the level of clusters of M-S-H globules-manual mixing resulted in an additional family of pores (around $30 \mathrm{~nm}$ ) that mechanically mixed pastes did not have, the latter only showing a family of mesopores centered on $10 \mathrm{~nm}$. The finer porosity of the mechanically mixed pastes can be explained by the reduction in $\mathrm{w} / \mathrm{b}$ due to increased mixing speed and power, which leads to denser and less porous pastes. On the smallest scale studied in this article (silica sheets), it seemed that the specific surface area and the amount of porosity increased when the M/S ratio decreased, while the size of the pores remained unaltered. M-S-H comprise a highly porous phase with plate-like micro- and mesopores and are sensitive to changes in humidity.

Author Contributions: Conceptualization, A.D., M.N., L.L., A.B. and C.D.; methodology, A.D., M.N., L.L., A.B. and C.D.; validation, A.D., M.N., L.L., A.B. and C.D.; investigation, C.D.; resources, A.D., M.N., L.L. and A.B.; writing-original draft preparation, C.D.; writing—review and editing, L.L., A.B., M.N. and A.D.; visualization, C.D.; supervision, A.D., M.N., L.L. and A.B.; project administration, L.L. and A.D.; funding acquisition, L.L. and A.D. All authors have read and agreed to the published version of the manuscript.

Funding: The author would like to thank IRSN (Institut de Radioprotection et de Sûreté Nucléaire/Institute for Radiation Protection and Nuclear Safety) and INSA Toulouse for funding this study.

Institutional Review Board Statement: Not applicable.

Informed Consent Statement: Not applicable.

Acknowledgments: The authors would like to thank Marja Siitari-Kauppi and Juuso Sammaljarvi for the work done at Helsinki University and Marc Begue for the work done at LMDC, INSA Toulouse. The authors are also grateful for the colloidal silica provided by BASF ${ }^{\circledR}$.

Conflicts of Interest: The authors declare no conflict of interest. The funders had no role in the design of the study; in the collection, analyses, or interpretation of data; in the writing of the manuscript, or in the decision to publish the results. 


\section{Appendix A}

Table A1. Polishing protocol of sections for MEB/EDS

\begin{tabular}{ccccccc}
\hline Step & $\begin{array}{c}\text { Abrasive } \\
\text { Paper }\end{array}$ & $\begin{array}{c}\text { Retention } \\
\text { Strength }\end{array}$ & $\begin{array}{c}\text { Speed } \\
(\mathbf{r d} / \mathbf{m i n})\end{array}$ & $\begin{array}{c}\text { Time } \\
(\mathbf{m i n})\end{array}$ & Abrasive Product & $\begin{array}{c}\text { Lubricant + Rinsing } \\
\text { Agent }\end{array}$ \\
\hline 1 & 240 & $30 \mathrm{~N}$ & 500 & $1-3$ & & Ethanol \\
2 & 1200 & $30 \mathrm{~N}$ & 250 & 1 & & Ethanol \\
3 & 2000 & $30 \mathrm{~N}$ & 250 & 1 & & Ethanol \\
4 & 4000 & $30 \mathrm{~N}$ & 250 & 1 & & Ethanol \\
5 & $3 \mu \mathrm{m}$ & Manual & 250 & 5 & Diamond powder $(3 \mu \mathrm{m})$ & Ethanol \\
6 & $1 \mu \mathrm{m}$ & Manual & 250 & 5 & Diamond powder $(1 \mu \mathrm{m})$ & Ethanol \\
\hline
\end{tabular}

\section{References}

1. Bonen, D.; Cohen, M.D. Magnesium Sulfate Attack on Portland Cement Paste-I. Microstructural Analysis. Cem. Concr. Res. 1992, 22, 169-180. [CrossRef]

2. Jakobsen, U.H.; De Weerdt, K.; Geiker, M.R. Elemental Zonation in Marine Concrete. Cem. Concr. Res. 2016, 85, 12-27. [CrossRef]

3. Santhanam, M.; Cohen, M.D.; Olek, J. Mechanism of Sulfate Attack: A Fresh Look: Part 1: Summary of Experimental Results. Cem. Concr. Res. 2002, 32, 915-921. [CrossRef]

4. De Weerdt, K.; Justnes, H. The Effect of Sea Water on the Phase Assemblage of Hydrated Cement Paste. Cem. Concr. Compos. 2015, 55, 215-222. [CrossRef]

5. Rosenqvist, M.; Bertron, A.; Fridh, K.; Hassanzadeh, M. Concrete Alteration Due to 55 years of Exposure to River Water: Chemical and Mineralogical Characterisation. Cem. Concr. Res. 2017, 92, 110-120. [CrossRef]

6. Dauzeres, A.; Achiedo, G.; Nied, D.; Bernard, E.; Alahrache, S.; Lothenbach, B. Magnesium Perturbation in Low-PH Concretes Placed in Clayey Environment-Solid Characterizations and Modeling. Cem. Concr. Res. 2016, 79, 137-150. [CrossRef]

7. García Calvo, J.L.; Hidalgo, A.; Alonso, C.; Fernández Luco, L. Development of Low-PH Cementitious Materials for HLRW Repositories: Resistance against Ground Waters Aggression. Cem. Concr. Res. 2010, 40, 1290-1297. [CrossRef]

8. Jenni, A.; Mäder, U.; Lerouge, C.; Gaboreau, S.; Schwyn, B. In Situ Interaction between Different Concretes and Opalinus Clay. Phys. Chem. Earth Parts A/B/C 2014, 70-71,71-83. [CrossRef]

9. Lerouge, C.; Gaboreau, S.; Grangeon, S.; Claret, F.; Warmont, F.; Jenni, A.; Cloet, V.; Mäder, U. In Situ Interactions between Opalinus Clay and Low Alkali Concrete. Phys. Chem. Earth Parts A/B/C 2017, 99, 3-21. [CrossRef]

10. Mäder, U.; Jenni, A.; Lerouge, C.; Gaboreau, S.; Miyoshi, S.; Kimura, Y.; Cloet, V.; Fukaya, M.; Claret, F.; Otake, T.; et al. 5-year chemico-physical evolution of concrete-claystone interfaces, Mont Terri rock laboratory (Switzerland). In Mont Terri Rock Laboratory, 20 Years: Two Decades of Research and Experimentation on Claystones for Geological Disposal of Radioactive Waste; Bossart, P., Milnes, A.G., Eds.; Springer International Publishing: Cham, Switzerland, 2018; pp. 309-329. ISBN 978-3-319-70458-6.

11. Alonso, M.C.; García Calvo, J.L.; Cuevas, J.; Turrero, M.J.; Fernández, R.; Torres, E.; Ruiz, A.I. Interaction Processes at the Concrete-Bentonite Interface after 13 Years of FEBEX-Plug Operation. Part I: Concrete Alteration. Phys. Chem. Earth Parts A/B/C 2017, 99, 38-48. [CrossRef]

12. Fernández, R.; Torres, E.; Ruiz, A.I.; Cuevas, J.; Alonso, M.C.; García Calvo, J.L.; Rodríguez, E.; Turrero, M.J. Interaction Processes at the Concrete-Bentonite Interface after 13 Years of FEBEX-Plug Operation. Part II: Bentonite Contact. Phys. Chem. Earth Parts $A / B / C$ 2017, 99, 49-63. [CrossRef]

13. Escadeillas, G.; Hornain, H. Chap 12: La Durabilité des Bétons Vis-A-Vis des Environnements Chimiquement Agressifs. In La Durabilité des Bétons; Presses des Ponts et Chaussées: Paris, France, 2008; pp. 613-705.

14. Jakobsen, U.H. Microstructural Surface Deterioration of Concrete Exposed to Seawater; Results after 2 Years Exposure. In Proceedings of the 14th Euroseminar on Microscopy Applied to Building Materials, Helsingør, Denmark, 10-14 June 2013.

15. Santhanam, M. Magnesium Attack of Cementitious Materials in Marine Environments. In Performance of Cement-Based Materials in Aggressive Aqueous Environments: State-of-the-Art Report, RILEM TC 211-PAE; Alexander, M., Bertron, A., De Belie, N., Eds.; RILEM State-of-the-Art Reports; Springer: Dordrecht, The Netherlands, 2013; pp. 75-90. ISBN 978-94-007-5413-3.

16. Buffo-Lacarrière, L.; Sellier, A.; Turatsinze, A.; Escadeillas, G. Finite Element Modelling of Hardening Concrete: Application to the Prediction of Early Age Cracking for Massive Reinforced Structures. Mater. Struct. 2011, 44, 1821-1835. [CrossRef]

17. Juenger, M.; Provis, J.L.; Elsen, J.; Matthes, W.; Hooton, R.D.; Duchesne, J.; Courard, L.; He, H.; Michel, F.; Snellings, R.; et al. Supplementary Cementitious Materials for Concrete: Characterization Needs. MRS Online Proc. Libr. OPL 2012, 1488, 8-22. [CrossRef]

18. Thomas, M.D.A.; Hooton, R.D.; Scott, A.; Zibara, H. The Effect of Supplementary Cementitious Materials on Chloride Binding in Hardened Cement Paste. Cem. Concr. Res. 2012, 42, 1-7. [CrossRef]

19. Lauch, K.-S.; Dieryck, V.; Pollet, V. The Use of Ternary Cements to Reduce the Environmental Impact of Concrete. RILEM Tech. Lett. 2016, 1, 88-93. [CrossRef]

20. Codina, M.; Cau-dit-Coumes, C.; Le Bescop, P.; Verdier, J.; Ollivier, J.P. Design and Characterization of Low-Heat and LowAlkalinity Cements. Cem. Concr. Res. 2008, 38, 437-448. [CrossRef] 
21. El Bitouri, Y.; Buffo-Lacarrière, L.; Sellier, A.; Bourbon, X. Modelling of Chemo-Mechanical Behaviour of Low PH Concretes. Cem. Concr. Res. 2016, 81, 70-80. [CrossRef]

22. Wang, L.; Yang, H.Q.; Zhou, S.H.; Chen, E.; Tang, S.W. Mechanical Properties, Long-Term Hydration Heat, Shinkage Behavior and Crack Resistance of Dam Concrete Designed with Low Heat Portland (LHP) Cement and Fly Ash. Constr. Build. Mater. 2018, 187, 1073-1091. [CrossRef]

23. Wang, L.; Jin, M.; Wu, Y.; Zhou, Y.; Tang, S. Hydration, Shrinkage, Pore Structure and Fractal Dimension of Silica Fume Modified Low Heat Portland Cement-Based Materials. Constr. Build. Mater. 2021, 272, 121952. [CrossRef]

24. Dauzères, A.; Le Bescop, P.; Cau-Dit-Coumes, C.; Brunet, F.; Bourbon, X.; Timonen, J.; Voutilainen, M.; Chomat, L.; Sardini, P. On the Physico-Chemical Evolution of Low-PH and CEM I Cement Pastes Interacting with Callovo-Oxfordian Pore Water under Its in Situ CO2 Partial Pressure. Cem. Concr. Res. 2014, 58, 76-88. [CrossRef]

25. Codina, M. Les Bétons Bas PH: Formulation, Caractérisation et Étude à Long Terme. Ph.D. Thesis, INSA de Toulouse, Toulouse, France, 2007.

26. Carde, C.; François, R.; Torrenti, J.-M. Leaching of Both Calcium Hydroxide and C-S-H from Cement Paste: Modeling the Mechanical Behavior. Cem. Concr. Res. 1996, 26, 1257-1268. [CrossRef]

27. Heukamp, F.H.; Ulm, F.-J.; Germaine, J.T. Mechanical Properties of Calcium-Leached Cement Pastes: Triaxial Stress States and the Influence of the Pore Pressures. Cem. Concr. Res. 2001, 31, 767-774. [CrossRef]

28. Heukamp, F.H.; Ulm, F.-J.; Germaine, J.T. Poroplastic Properties of Calcium-Leached Cement-Based Materials. Cem. Concr. Res. 2003, 33, 1155-1173. [CrossRef]

29. Nguyen, V.H.; Colina, H.; Torrenti, J.M.; Boulay, C.; Nedjar, B. Chemo-Mechanical Coupling Behaviour of Leached Concrete: Part I: Experimental Results. Nucl. Eng. Des. 2007, 237, 2083-2089. [CrossRef]

30. Sellier, A.; Buffo-Lacarrière, L.; Gonnouni, M.E.; Bourbon, X. Behavior of HPC Nuclear Waste Disposal Structures in Leaching Environment. Nucl. Eng. Des. 2011, 241, 402-414. [CrossRef]

31. Liu, L.; Sun, C.; Geng, G.; Feng, P.; Li, J.; Dähn, R. Influence of Decalcification on Structural and Mechanical Properties of Synthetic Calcium Silicate Hydrate (C-S-H). Cem. Concr. Res. 2019, 123, 105793. [CrossRef]

32. Nied, D.; Enemark-Rasmussen, K.; L’Hopital, E.; Skibsted, J.; Lothenbach, B. Properties of Magnesium Silicate Hydrates (M-S-H). Cem. Concr. Res. 2016, 79, 323-332. [CrossRef]

33. Roosz, C.; Grangeon, S.; Blanc, P.; Montouillout, V.; Lothenbach, B.; Henocq, P.; Giffaut, E.; Vieillard, P.; Gaboreau, S. Crystal Structure of Magnesium Silicate Hydrates (M-S-H): The Relation with 2:1 Mg-Si Phyllosilicates. Cem. Concr. Res. 2015, 73, 228-237. [CrossRef]

34. D’Espinose de la Caillerie, J.-B.; Kermarec, M.; Clause, O. 29Si NMR Observation of an Amorphous Magnesium Silicate Formed during Impregnation of Silica with Mg(II) in Aqueous Solution. J. Phys. Chem. 1995, 99, 17273-17281. [CrossRef]

35. Brew, D.R.M.; Glasser, F.P. Synthesis and Characterisation of Magnesium Silicate Hydrate Gels. Cem. Concr. Res. 2005, 35, 85-98 [CrossRef]

36. Bernard, E.; Lothenbach, B.; Rentsch, D.; Pochard, I.; Dauzères, A. Formation of Magnesium Silicate Hydrates (M-S-H). Phys. Chem. Earth Parts A/B/C 2017, 99, 142-157. [CrossRef]

37. Bernard, E.; Lothenbach, B.; Cau-Dit-Coumes, C.; Chlique, C.; Dauzères, A.; Pochard, I. Magnesium and Calcium Silicate Hydrates, Part I: Investigation of the Possible Magnesium Incorporation in Calcium Silicate Hydrate (C-S-H) and of the Calcium in Magnesium Silicate Hydrate (M-S-H). Appl. Geochem. 2018, 89, 229-242. [CrossRef]

38. Lothenbach, B.; Nied, D.; L’Hôpital, E.; Achiedo, G.; Dauzères, A. Magnesium and Calcium Silicate Hydrates. Cem. Concr. Res. 2015, 77, 60-68. [CrossRef]

39. Zhang, T.; Zou, J.; Wang, B.; Wu, Z.; Jia, Y.; Cheeseman, C.R. Characterization of Magnesium Silicate Hydrate (MSH) Gel Formed by Reacting $\mathrm{MgO}$ and Silica Fume. Materials 2018, 11, 909. [CrossRef]

40. Roosz, C.; Vieillard, P.; Blanc, P.; Gaboreau, S.; Gailhanou, H.; Braithwaite, D.; Montouillout, V.; Denoyel, R.; Henocq, P.; Madé, B Thermodynamic Properties of C-S-H, C-A-S-H and M-S-H Phases: Results from Direct Measurements and Predictive Modelling. Appl. Geochem. 2018, 92, 140-156. [CrossRef]

41. Bernard, E.; Lothenbach, B.; Le Goff, F.; Pochard, I.; Dauzères, A. Effect of Magnesium on Calcium Silicate Hydrate (C-S-H). Cem. Concr. Res. 2017, 97, 61-72. [CrossRef]

42. Bernard, E.; Dauzères, A.; Lothenbach, B. Magnesium and Calcium Silicate Hydrates, Part II: Mg-Exchange at the Interface "Low-PH" Cement and Magnesium Environment Studied in a C-S-H and M-S-H Model System. Appl. Geochem. 2018, 89, 210-218. [CrossRef]

43. Bernard, E.; Lothenbach, B.; Chlique, C.; Wyrzykowski, M.; Dauzères, A.; Pochard, I.; Cau-Dit-Coumes, C. Characterization of Magnesium Silicate Hydrate (M-S-H). Cem. Concr. Res. 2019, 116, 309-330. [CrossRef]

44. Tonelli, M.; Martini, F.; Calucci, L.; Geppi, M.; Borsacchi, S.; Ridi, F. Traditional Portland Cement and MgO-Based Cement: A Promising Combination? Phys. Chem. Earth Parts A/B/C 2017, 99, 158-167. [CrossRef]

45. Zhang, T.; Vandeperre, L.J.; Cheeseman, C.R. Formation of Magnesium Silicate Hydrate (M-S-H) Cement Pastes Using Sodium Hexametaphosphate. Cem. Concr. Res. 2014, 65, 8-14. [CrossRef]

46. Tonelli, M.; Martini, F.; Calucci, L.; Fratini, E.; Geppi, M.; Ridi, F.; Borsacchi, S.; Baglioni, P. Structural Characterization of Magnesium Silicate Hydrate: Towards the Design of Eco-Sustainable Cements. Dalton Trans. 2016, 45, 3294-3304. [CrossRef] 
47. Sonat, C.; Unluer, C. Development of Magnesium-Silicate-Hydrate (M-S-H) Cement with Rice Husk Ash. J. Clean. Prod. 2019, 211, 787-803. [CrossRef]

48. Hesaraki, S.; Zamanian, A.; Moztarzadeh, F. Effect of Adding Sodium Hexametaphosphate Liquefier on Basic Properties of Calcium Phosphate Cements. J. Biomed. Mater. Res. Part A 2009, 88A, 314-321. [CrossRef]

49. Jia, Y.; Wang, B.; Wu, Z.; Han, J.; Zhang, T.; Vandeperre, L.J.; Cheeseman, C.R. Role of Sodium Hexametaphosphate in $\mathrm{MgO} / \mathrm{SiO}_{2}$ Cement Pastes. Cem. Concr. Res. 2016, 89, 63-71. [CrossRef]

50. Tonelli, M.; Martini, F.; Milanesi, A.; Calucci, L.; Geppi, M.; Borsacchi, S.; Ridi, F. Effect of Phosphate Additives on the Hydration Process of Magnesium Silicate Cements. J. Anal. Calorim. 2019, 138, 3311-3321. [CrossRef]

51. Bernard, E. Magnesium Silicate Hydrate (M-S-H) Characterization: Temperature, Calcium, Aluminium and Alkali. Ph.D. Thesis, Université Bourgogne Franche-Comté, Bourgogne Franche-Comté, France, 2017.

52. Lothenbach, B.; Durdziński, P.; De Weerdt, K. Chapter 5: Thermogravimetric analysis. In A Practical Guide to Microstructural Analysis of Cementitious Materials; CRC Press: Boca Raton, FL, USA, 2016; pp. 177-212. ISBN 978-1-4987-3867-5.

53. Mehta, P.; Monteiro, P.J.M. Concrete: Microstructure, Properties, and Materials: Microstructure, Properties, and Materials; McGraw Hill Professional: New York, NY, USA, 2005; ISBN 978-0-07-146289-1.

54. Sardini, P.; Siitari-Kauppi, M.; Beaufort, D.; Hellmuth, K.-H. On the Connected Porosity of Mineral Aggregates in Crystalline Rocks. Am. Mineral. 2006, 91, 1069-1080. [CrossRef]

55. Hellmuth, K.H.; Siitari-Kauppi, M.; Lindberg, A. Study of Porosity and Migration Pathways in Crystalline Rock by Impregnation with 14C-Polymethylmethacrylate. J. Contam. Hydrol. 1993, 13, 403-418. [CrossRef]

56. Hellmuth, K.-H.; Lukkarinen, S.; Siitari-kauppi, M. Rock Matrix Studies with Carbon-14-Polymethylmethacrylate (PMMA); Method Development and Applications. Isot. Isot. Environ. Health Stud. 1994, 30, 47-60. [CrossRef]

57. Sammaljärvi, J.; Shroff Rama, M.; Ikonen, J.; Muuri, E.; Hellmuth, K.-H.; Siitari-Kauppi, M. Free Radical Polymerisation of Methacrylates with Thermal Initiator in Clay Rock. Eng. Geol. 2016, 210, 70-83. [CrossRef]

58. Lalan, P.; Dauzères, A.; De Windt, L.; Sammaljärvi, J.; Bartier, D.; Techer, I.; Detilleux, V.; Siitari-Kauppi, M. Mineralogical and Microstructural Evolution of Portland Cement Paste/Argillite Interfaces at $70{ }^{\circ} \mathrm{C}$-Considerations for Diffusion and Porosity Properties. Cem. Concr. Res. 2019, 115, 414-425. [CrossRef]

59. Sammaljärvi, J.; Jokelainen, L.; Ikonen, J.; Siitari-Kauppi, M. Free Radical Polymerisation of MMA with Thermal Initiator in Brick and Grimsel Granodiorite. Eng. Geol. 2012, 135-136, 52-59. [CrossRef]

60. Delayre, C.; Sammaljärvi, J.; Billon, S.; Muuri, E.; Sardini, P.; Siitari-Kauppi, M. Comparison of Phosphor Screen Autoradiography and Micro-Pattern Gas Detector Based Autoradiography for the Porosity of Altered Rocks. Sci. Rep. 2020, 10, 9455. [CrossRef]

61. Galarneau, A.; Mehlhorn, D.; Guenneau, F.; Coasne, B.; Villemot, F.; Minoux, D.; Aquino, C.; Dath, J.-P. Specific Surface Area Determination for Microporous/Mesoporous Materials: The Case of Mesoporous FAU-Y Zeolites. Langmuir 2018, 34, 14134-14142. [CrossRef] [PubMed]

62. De Boer, J.H.; Lippens, B.C.; Linsen, B.G.; Broekhoff, J.C.P.; van den Heuvel, A.; Osinga, T.H.J. Thet-Curve of Multimolecular N2-Adsorption. J. Colloid Interface Sci. 1966, 21, 405-414. [CrossRef]

63. Barrett, E.P.; Joyner, L.G.; Halenda, P.P. The Determination of Pore Volume and Area Distributions in Porous Substances. I. Computations from Nitrogen Isotherms. J. Am. Chem. Soc. 1951, 73, 373-380. [CrossRef]

64. Monnier, G.; Stengel, P.; Fies, J.C. Une Méthode de Mesure de La Densité Apparente de Petits Agglomérats Terreux. Application à l'analyse Des Systèmes de Porosité Du Sol. Ann. Agron. 1973, 24, 533-545.

65. French Standard X31-505; Qualité des Sols-Méthodes Physiques-Méthode de Détermination du Volume Apparent et du Contenu en eau des Mottes. AFNOR: Paris, France, 1992; 12p.

66. Li, Z.; Zhang, T.; Hu, J.; Tang, Y.; Niu, Y.; Wei, J.; Yu, Q. Characterization of Reaction Products and Reaction Process of $\mathrm{MgO}-\mathrm{SiO}_{2}-\mathrm{H}_{2} \mathrm{O}$ System at Room Temperature. Constr. Build. Mater. 2014, 61, 252-259. [CrossRef]

67. Dumas, A.; Martin, F.; Le Roux, C.; Micoud, P.; Petit, S.; Ferrage, E.; Brendlé, J.; Grauby, O.; Greenhill-Hooper, M. Phyllosilicates Synthesis: A Way of Accessing Edges Contributions in NMR and FTIR Spectroscopies. Example of Synthetic Talc. Phys. Chem. Miner. 2013, 40, 361-373. [CrossRef]

68. Zhuravlev, L.T. The Surface Chemistry of Amorphous Silica. Zhuravlev Model. Colloids Surf. A Physicochem. Eng. Asp. 2000, 173, 1-38. [CrossRef]

69. Grangeon, S.; Claret, F.; Roosz, C.; Sato, T.; Gaboreau, S.; Linard, Y. Structure of Nanocrystalline Calcium Silicate Hydrates: Insights from X-ray Diffraction, Synchrotron X-ray Absorption and Nuclear Magnetic Resonance. J. Appl. Cryst. 2016, 49, 771-783. [CrossRef]

70. Sing, K.S.W. Reporting physisorption data for gas/solid systems with special reference to the determination of surface area and porosity (Recommendations 1984). Pure Appl. Chem. 1985, 57, 603-619. [CrossRef]

71. Bardestani, R.; Patience, G.S.; Kaliaguine, S. Experimental Methods in Chemical Engineering: Specific Surface Area and Pore Size Distribution Measurements-BET, BJH, and DFT. Can. J. Chem. Eng. 2019, 97, 2781-2791. [CrossRef]

72. Bisio, C.; Gatti, G.; Boccaleri, E.; Marchese, L.; Superti, G.B.; Pastore, H.O.; Thommes, M. Understanding Physico-Chemical Properties of Saponite Synthetic Clays. Microporous Mesoporous Mater. 2008, 107, 90-101. [CrossRef]

73. Richardson, I.G. The Nature of C-S-H in Hardened Cements. Cem. Concr. Res. 1999, 29, 1131-1147. [CrossRef] 
74. Kangni-Foli, E. Apport de Matériaux Cimentaires Modèles à La Description Des Cinétiques de Carbonatation de Bétons Bas-PH: Conséquences Sur La Microstructure Le Transport de Gaz et Les Déformations. Ph.D. Thesis, Paris Sciences et Lettres, Paris, France, 2019.

75. Bernard, E.; Lothenbach, B.; Cau-Dit-Coumes, C.; Pochard, I.; Rentsch, D. Aluminum Incorporation into Magnesium Silicate Hydrate (M-S-H). Cem. Concr. Res. 2020, 128, 105931. [CrossRef]

76. Shah, V.; Scott, A. Hydration and Microstructural Characteristics of MgO in the Presence of Metakaolin and Silica Fume. Cem. Concr. Compos. 2021, 121, 104068. [CrossRef] 